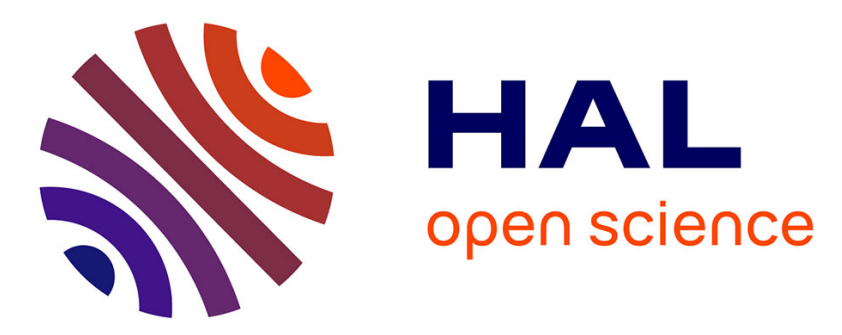

\title{
Effects of motorcycle simulator configurations on steering control and gaze behavior in bends.
}

Régis Lobjois, Franck Mars

\section{To cite this version:}

Régis Lobjois, Franck Mars. Effects of motorcycle simulator configurations on steering control and gaze behavior in bends.. Journal of Experimental Psychology: Applied, 2020, 26 (1), pp.108-123. $10.1037 /$ xap0000241 . hal-02279075

\section{HAL Id: hal-02279075 \\ https://hal.science/hal-02279075}

Submitted on 7 May 2020

HAL is a multi-disciplinary open access archive for the deposit and dissemination of scientific research documents, whether they are published or not. The documents may come from teaching and research institutions in France or abroad, or from public or private research centers.
L'archive ouverte pluridisciplinaire HAL, est destinée au dépôt et à la diffusion de documents scientifiques de niveau recherche, publiés ou non, émanant des établissements d'enseignement et de recherche français ou étrangers, des laboratoires publics ou privés. 
This is a preprint version of the following article:

Lobjois, R. \& Mars, F. (2020). Effects of motorcycle simulator configurations on steering control and gaze behavidr in bends. Journal of Experimental Psychology: Applied, 26(1), 108-123. doi:10.1037/xap0000241

The published version can be found here: https://doi.org/10.1037/xap0000241

Effects of motorcycle simulator configurations on steering control and gaze behavior in bends

$$
\text { Régis Lobjois }{ }^{1} \text { and Franck Mars }{ }^{2}
$$

${ }^{1}$ Laboratory for Road Operations, Perception, Simulators and Simulation

French Institute of Sciences and Technology for Transport, Development and Networks

${ }^{2}$ Laboratoire des Sciences du Numérique de Nantes - UMR CNRS 6004

CNRS \& Centrale Nantes

\section{Author Note}

This research was supported by a grant from the Fondation Sécurité Routière for the SENSORIMOTO project. The authors would like to thank Stéphane Caro and Fabrice Vienne for their help in preparing the simulator and communication with the eye-tracker, respective1y. The authors are grateful to Susan Watts for English-language proofreading.

Corresponding author:

Régis Lobjois

Laboratory for Road Operations, Perception, Simulators and Simulation

French Institute of Sciences and Technology for Transport, Development and Networks

Paris-Est University

14-20 Boulevard Newton, Cité Descartes

Champs sur Marne, F-77447 Marne la Vallée Cedex 2, France

Phone: +33181668346. 


\begin{abstract}
The recent development of motorcycle simulators has made it possible to study rider behavior in safe conditions. However, their use still raises validity issues. Our study examined how riders' steering and gaze behaviors and subjective experience are influenced by motorcycle roll tilt and reverse steering, which are considered to be essential factors in real-life motorcycle riding. The results revealed that tilting the motorcycle in the roll plane did not lead to significant changes in rider behavior, gaze sampling or perceived realism. The steering control strategy adopted by riders did, however, significantly influence these results. A direct steering control strategy meant that riders took a racing path and scanned the road far in advance. When reverse steering was implemented, however, riders chose to take a "safety path", as recommended by training manuals. Reverse steering also received the highest realism score. However, steering control was more difficult, as shown by the larger number of lane departures recorded and a change in the trade-off between guiding and look-ahead fixations. This suggests that although reverse steering matches riders' real control behavior and improves the subjective experience of simulator riding, it is hindered by an inadequate internal model of vehicle dynamics.
\end{abstract}

\title{
Public Significance Statement
}

Increasing physical fidelity of a motorcycle simulator led to improved subjective realism and riding behavior but impaired steering control underlying processes. These results provide an objective basis for researchers to select the type of simulator adapted to their research needs.

Keywords: motorcycle simulator, reverse steering, bend negotiation, steering path, visual control of steering 
Effects of motorcycle simulator configurations on steering control and gaze behavior in bends

Current road safety statistics show that the number of road deaths is falling. However, the risk of motorcyclists being killed on the road remains 25 times higher than that of car drivers for the same number of kilometers driven (NHTSA, 2016; ONISR, 2007). In countries of the Organization for Economic Co-operation and Development (OECD), between 2000 and 2010 , traffic-related fatalities decreased by $36 \%$, whilst this percentage for motorcyclists decreased by only 13\% (OECD/ITF, 2015). In France, motorcycle fatalities increased by $13.3 \%$ in 2009 (ONISR, 2010). Likewise, in the United States, motorcyclists fatalities increased by 44\% between 2001 and 2011, whilst those of passenger car occupant decreased by 29\%. With regard to types of crashes, around 36\% of total motorcycle fatalities in France are single vehicle crashes. A large proportion (39\%) occur on rural roads and $45 \%$ of them during bend negotiation (ONISR, 2010; see also Clarke, Ward, Bartle, \& Truman, 2007).

The recent development of motorcycle simulators has made it possible to study rider behavior when negotiating bends (Crundall, Crundall, \& Stedmon, 2012), approaching intersections (Crundall, Stedmon, Saikayasit, \& Crundall, 2013) and perceiving hazards (Liu, Hosking, \& Lenné, 2009). Motorcycle simulators have also been used to assess rider cognitive skills (Di Stasi et al., 2009) and test assistance systems (Huth, Biral, Martín, \& Lot, 2012). Whilst research has focused more and more on rider behavior, the use of motorcycle simulators to study rider behavior still raises validity issues (Benedetto et al., 2014; Cossalter, Lot, \& Rota, 2010; Crundall, Stedmon, Crundall, \& Saikayasit, 2014; Stedmon et al., 2011). Virtual reality (VR) systems are designed to better understand human behavior. However, it is widely accepted that while their physical fidelity, i.e. the extent to which they replicate the real situation, is a key point for the participant's ability to act naturally in the virtual environment (Slater, 2009), it is impossible to achieve due to technological limitations (Grechkin, Plumert, \& Kearney, 2014; Pinto, Cavallo, \& Ohlmann, 2008). Therefore, choices 
that are made about the systems properties to improve the physical fidelity have an impact on

users and these effects must be assessed. Different dimensions of fidelity have been used to evaluate VR systems in relation to human behavior (Malaterre \& Fréchaux, 2001; Morice, Siegler, \& Bardy, 2008; Pinto et al., 2008). Subjective fidelity refers to the degree to which the simulated experience is subjectively close to the real situation. Behavioral fidelity is defined as the correspondence of the observed behavior between the simulated and the real system. Finally, psychological fidelity corresponds to the similarity of the psychological processes underlying the activity. A small pool of studies has highlighted that these three dimensions of fidelity could be more or less sensitive to the properties of a VR system.

Concerning the relation between subjective and behavioral fidelities, Morice et al. (2008) showed that behavior may be deteriorated by the system properties whilst subjective experience remains good. In a virtual ball-bouncing task, the participants reported system latency for relatively high delays whilst bouncing performance deteriorated for small ones. In motorcycle riding simulation, Lobjois, Siegler, and Mars (2016b) showed that the introduction of visual roll was always preferred to no roll although large visual roll altered driving performance. On the other hand, the combined evaluation of behavioral and psychological dimensions of fidelity also suggests discrepancy between these two dimensions. To date, psychological fidelity in driving simulation has been assessed through the measurement of mental workload, which is the result of the interaction between task demands and the attentional resources capacity of the operator (Borghini et al., 2014; Recarte \& Nunes, 2003). According to the mental workload model in driving from de Waard (1996), behavioral measures (e.g., vehicle handling) may be similar in simulated and on-road driving, but with different level of associated mental workload. If mental workload is the same in the two conditions, it can be assumed that the simulator does not place more demands on vehicle handling. The process of controlling the vehicle, which is essentially automated and does not request attentional re- 
sources, is not made difficult by the imperfections of the driving simulation. On the contrary,

a higher mental workload suggests that simulated driving makes the vehicle handling more demanding and that more attentional resources must be allocated to maintain driving performance. Empirical results showed that even when vehicle handling is well preserved in a simulator, subjective workload ratings may be higher (Alm, 1995; Blaauw, 1982; Diels, Robbins, \& Reed, 2011). Using a cognitive secondary task to measure mental workload level in a primary (driving) task, Reimer and Mehler (2011) and Mehler, Reimer, Coughlin, and Dusek. (2009) showed in two separated studies sharing the same experimental manipulation that when difficulty of the secondary task increased, response accuracy decreased more in the simulator (Mehler et al., 2009) than in actual driving conditions (Reimer \& Mehler, 2011). Although they focused on mental workload, these studies suggest that measures of psychological fidelity are also called for in-depth evaluation of VR systems.

Following on from these considerations, the goal of the present study was to contribute to the development of motorcycle simulators for studying motorcyclists' riding behavior. To this aim, the physical fidelity was manipulated so that its effects could be assessed at the level of subjective experience (subjective fidelity) and steering strategy (behavioral fidelity). In particular, increasing physical fidelity was assumed to improve subjective and behavioral fidelity. As steering a vehicle is visually guided, the effects of physical fidelity were in addition assessed at the level of gaze dynamics (psychological fidelity) to explore whether the visual guidance of steering is altered when physical fidelity is increased.

Tilting the motorcycle into a bend and reverse steering are two important contributors to the physical fidelity of motorcycle simulation (Benedetto et al., 2014; Cossalter et al., 2010; Crundall et al., 2014; Stedmon et al., 2011). Reverse steering is specific to motorcycles (and to a lesser extent to bicycles); it relates to their mechanical conception and the gyroscopic effect of the front wheel. Reverse steering is defined as the rider's action of briefly steering 
the handlebar in the opposite direction to the turn of the road, with the result that the motorcy-

cle leans into the bend. The heavier and faster the motorcycle, the greater the influence of reverse steering, because shifting the body weight becomes less effective (Fajans, 1999).

Crundall et al. (2012) pointed out that motorcyclists steering path could be guided by two strategies. The first one, the 'racing line', is motivated by speed maintenance and course curvature reduction. Riders steer from the outside edge of their lane to the inside edge when approaching the apex before they move back to the outside part of the lane to exit the curve. This corner-cutting strategy allows smoother and faster trajectories to be taken, albeit at the expense of the visibility of the bend curvature and trajectory planning (when the view of the bend is occluded). The second strategy, the 'safety path', is based on acquiring as much visibility as possible towards the final part of the bend. To this end, riders maintain their position in the outside part of the lane before changing direction. As a consequence, riders cross the centerline of their lane further along the bend. This steering strategy is recommended in the training manuals and by police motorcycle trainers. Empirical results showed a tendency in motorcyclists to steer into bends according to a 'racing line' rather than a 'safety path' strategy. Lobjois et al. (2016b) showed that the in-lane position adopted by motorcyclists was shifted towards the inner edge line with a standard deviation of $30 \mathrm{~cm}$, suggesting that they negotiated bends by spending most of the time in the inside part of the lane. Crundall et al. (2014) revealed a similar 'racing line' strategy. Investigating the effects of rider experience on steering strategies, Crundall et al. (2012) showed that riders crossed the lane center before the apex of the bend, suggesting that they preferentially adopted a 'racing path'. However, this was mitigated by experience. Advanced riders crossed the center of the lane further through the bend compared to novice and experienced riders, which is closer to the 'safety path' strategy. Whilst Crundall et al. (2012) elicited the expected experience-related differences between groups of riders, the above-mentioned studies all used static motorcycle simulators, 
with steering control based on a direct steering control model (i.e., turning the handlebar in

the same direction as the turn). As acknowledged by Crundall et al. (2014), the lack of physical fidelity may have affected riders' behavior in bends. This gives rise to the question of whether the introduction of roll motion and reverse steering would influence subjective experience and steering strategy in a bend negotiation task.

To our knowledge, only one study has compared the effects of a static motorcycle simulator with a direct steering control model and a dynamic model with reverse steering on rider behavior (Benedetto et al., 2014). In a lane changing task, the authors examined subjective evaluation, performance and mental workload measures. Subjective results showed that the dynamic configuration was judged as being more realistic than the static one although it was more difficult to familiarize with. Objective measures revealed that the dynamic configuration triggered a greater workload than the static one during the first occurrence; however, this additional mental workload level decreased with further repetitions. The higher mental workload in the dynamic configuration may be explained by higher demands placed upon steering control. Despite this, the deviation between the riders' actual trajectory and the optimal path in the lane change maneuver did not vary between simulator configurations. On the other hand, the average delay before lane change initiation was longer in the dynamic configuration than in the static one. But, whilst mental workload decreased with repetition, the lane change delay did not. Combined with the observation that steering control was not impaired, the riders may have postponed the lane change maneuver because the reverse steering control model is the most efficient way to rapidly change the direction of the motorcycle.

With regard to steering strategy in high-speed locomotion tasks, it is well known that steering control is tightly coupled with gaze dynamics (e.g., Land \& Lee, 1994; Mars, 2008; Wilkie, Kountouriotis, Merat, \& Wann, 2010). Thus, to have a fine grained understanding of 
the effects of simulator configuration on the underlying processes of steering control (psycho-

logical fidelity), the gaze dynamics and visual strategies may also be addressed.

So-called two-level control models represent two distinct visual processes that determine the visual control of steering (Donges, 1978; Mars, Saleh, Chevrel, Claveau, \& Lafay, 2011; Salvucci \& Gray, 2004). Compensatory corrections of a vehicle's lateral deviation from the intended path presumably rely on peripheral vision, which brings into view the edge lines relatively close to the vehicle (Summala, Nieminen, \& Punto, 1996). More distant visual information is acquired by guiding fixations, which feed anticipatory control (Frissen \& Mars, 2014; Land \& Horwood, 1995). Recently, it has been shown that fixations that are even more anticipatory, called look-ahead fixations, are a way of bringing about advance path planning and hazard detection (Lehtonen, Lappi, Koirikivi, \& Summala, 2014; Lehtonen, Lappi, Kotkanen, \& Summala, 2013; Mars \& Navarro, 2012; Wilkie, Wann, \& Allison, 2008). Lookahead fixations are fixations on the road further ahead, most often in an eccentric position, disengaging gaze from the online visual guidance of steering (Lehtonen et al., 2014). For example, Wilkie et al. (2008) observed a dual-sampling strategy among cyclists negotiating a slalom which consisted of fixating the next gate while approaching the current one. Since the gaze cannot be directed toward two locations at a time, a trade-off exists between guiding and look-ahead fixations and some studies have highlighted that this trade-off is influenced, among other things (e.g., driving experience, curve sequence; Lehtonen et al., 2013, 2014), by the demands placed on steering control and cognitive load. Mars and Navarro (2012) compared gaze behavior when drivers actively steered the vehicle and when steering was performed by an automatic controller and showed that the number of look-ahead fixations increased and the number of guiding fixations decreased in the passive steering condition. Because the active steering condition placed more demands on steering guidance, drivers were less able to assess road curvature in the far distance. Lehtonen, Lappi, and Summala (2012) 
further found that the time spent on look-ahead fixations tends to shorten when drivers had to

perform a cognitive secondary task. Whilst this effect was observed in the approach phase, this suggests that visual anticipation in driving is affected by cognitive load.

Based on these results, the present study aimed to investigate the effects of riding simulator configuration on motorcyclists' subjective experience and riding behavior in a bend negotiation task. Three simulator configurations were tested in order to examine the respective effects of tilting the motorcycle and reverse steering on rider behavior. The simulator configuration could be either static with a direct steering control model, dynamic with a direct steering control model or dynamic with a reverse steering control model. We hypothesized that increasing the physical fidelity of the motorcycle simulator by introducing roll tilt rendering and reverse steering may improve its subjective and behavioral fidelity. At the subjective level, this would result in an enhanced subjective experience as measured by the presence score. At the behavioral level, this would result in the adoption of a 'safety path' strategy. In accordance with earlier description, motorcyclists would then maintain their lateral position in the outer part of the lane for a longer time so that they would cross the lane center at a point further along the bend. On the contrary, a 'racing line' strategy based on speed maintenance and course curvature reduction may be adopted as shown previously in a no-roll or direct steering configuration (Crundall et al., 2012; 2014; Lobjois et al., 2016b). In addition to this, we also tracked potential drawbacks of increased physical fidelity at the level of steering control underlying processes. Given that increased fidelity of a motorcycle simulator increased steering control demands and riders' mental workload (Benedetto et al., 2014), and that both of which are known to mitigate visual anticipation in driving (Lehtonen et al., 2012; Mars \& Navarro, 2012), we hypothesized that the way the guiding and look-ahead fixations are distributed would be affected by the simulator configuration. This would result in an increase in the proportion of guiding fixations and a concomitant decrease of look-ahead fixations with 
the reverse steering configuration. We at last assessed sickness symptoms to address whether

\section{Method}

\section{Participants}

Eighteen participants (17 males, 1 female) were recruited through advertisements on motorcyclists' forums and through motorcyclist associations, as well as the web page of a motorcycle newspaper. Participants had a mean age of $32.1 \pm 6.4$ years, ranging from 24 to 48 years old. Their mean motorcycle license seniority was $7.3 \pm 3.5$ years and they rode 11,916 $\mathrm{km}$ a year, on average. All participants had normal or corrected-to-normal vision, and were naïve as to the aims and expected outcomes of the experiment. The study was approved by the local Ethics Committee and a compensation payment of $40 €$ for each person was agreed. The ethical considerations and principles of the World Medical Association Declaration of Helsinki regarding experimentation were respected.

\section{Experimental set-up}

The experiment was conducted on a powered motion-based motorcycle simulator (see Figure 1). This simulator comprised a motion platform, image-generation software, projection screen, and a sound system. It consisted of a standard motorcycle frame $(125 \mathrm{cc})$ equipped with all the necessary parts, including a steering column with handlebars, gas tank, seat, footrests, throttle, front and rear brakes, and gear shifting devices. The steering column was equipped with a force feedback motor and steering feedback was refreshed at a frequency of $100 \mathrm{~Hz}$. When dynamic, the motion of the motorcycle in the roll axis was obtained by two lateral electric actuators that replaced the front fork. The rolling centre was located approximately $30 \mathrm{~cm}$ below the simulator's seat. The highest roll angle was $\pm 12.5^{\circ}$ due to actuator limitations. Motion was refreshed at a frequency of $250 \mathrm{~Hz}$. In accordance with real-life riding, higher speeds and larger lean angles resulted in faster movement of the motorcycle simu- 
lator. The simulator concept, design and functioning have been fully described in Arioui,

Nehaoua, Hima, Séguy, and Espié (2010).

The simulated scene was displayed onto a white screen that was $185 \mathrm{~cm}$ wide $\mathrm{x}$ $124 \mathrm{~cm}$ high, subtending a visual angle of $60 \times 40^{\circ}$. Participants faced the screen at a distance of approximately $165 \mathrm{~cm}$ when seated on the simulator. The images (refreshed at $30 \mathrm{~Hz}$ ) were calculated and projected at the participant's eye height, and the simulated viewing angle was aimed at the vanishing point of the simulated scenario. Simulated engine sounds were provided by using a 4.1 speaker system.

The fully textured visual scene represented a single carriageway on a winding road with standard white lane markings in a traffic-free environment. The simulated route was a two-lane rural road, with one lane in each direction (the participants rode on the right-hand lane). The width of each lane was $3.5 \mathrm{~m}$ (for a cross-sectional width of $7 \mathrm{~m}$, including road markings) and the road was lined with trees. The track covered a total distance of $6.240 \mathrm{~km}$. It consisted of 12 left- and 8 right-hand bends that were separated by a $100 \mathrm{~m}$ section of straight road. Bend curvature was either $150 \mathrm{~m}$ or $300 \mathrm{~m}$.

In this environment, participants were invited to find a comfortable riding position with their head upright, their feet off the ground and in place on the footrests. They were asked to perform the task as if they were riding for real, observing a target speed of around 90 $\mathrm{km} / \mathrm{h}$. They were told that they could freely negotiate the bends and position themselves in their lane, but were explicitly asked to keep the vehicle within the lane boundaries.

A Pertech head-mounted monocular eye tracker was used to record participants' ocular behavior with a sampling rate of $50 \mathrm{~Hz}$. This device, based on the principle of a pair of glasses (without lenses), has $0.25^{\circ}$ of accuracy (according to the manufacturer specification) and uses pupil-tracking technology with an image-processing algorithm to define the ocular direction. A seven-point calibration was performed for each participant at the beginning of 
each experimental trial. Room lighting was kept constant during all the experimental trials.

The eye tracker and the simulator were synchronized and the communication between the two devices was established so that data about the 3D world and riding behavior were sent to the eye tracker software. This enabled us to automatically analyze gaze directions relative to the visual features of the scene and any riding measures.

\section{Motorcycle simulator configurations}

Three different riding configurations were implemented and tested. In the fixed-base with direct steering configuration, the mock-up was static. As such, the motorcycle did not lean into bends and direct steering consisted in turning the handlebar in the desired direction (i.e., steer left to turn left). In the motion-based with direct steering configuration, the motorcycle mock-up leaned into bends and the steering control model was identical to the first configuration. In the motion-based with reverse steering configuration, the motorcycle mock-up also leaned into bends but the steering control model consisted in steering counter to the desired direction (i.e., steer left to turn right).

In all three configurations, the visual scene was rolled in the opposite direction to the bend. This visually specified roll tilt was selected since it has been shown to elicit a feeling of leaning into a bend, even when the mock-up is static (Stedmon et al., 2011). The visual gain was set at 0.5 , which corresponds to the rendering of $50 \%$ of the leaning angle of a real motorcycle with similar speeds and path curvature conditions.

In the two motion-based configurations, the motorcycle gain was set at 0.4 , which reproduced $40 \%$ of the leaning angle of a real motorcycle with similar speeds and path curvature conditions. This motorcycle gain was selected so that the motion range was limited to avoid the sensation of falling off the simulator (Lobjois, Dagonneau, \& Isableu, 2016a).

In the two direct steering configurations, the roll angle was proportional to the speed of the motorcycle and the steering angle of the handlebar. The more the riders turned the han- 
dlebar and/or the faster they rode, the greater the rolling angle. The magnitude of force feedback also depended on the handlebar steering angle and motorcycle speed. When no force was applied on the handlebar, it came back to its neutral position $\left(0^{\circ}\right)$ in relation to the motorcycle and/or visual scene.

In the reverse steering configuration, the roll angle was the result of the integration of motorcycle speed and handlebar steering angle. This was the result of riders basing their control of steering not on the handlebar steering angle per se but on the applied steering torque (Fajans, 1999; Nehaoua, Arioui, \& Mammar, 2013). To this end, the sensitivity of the force feedback motor and force feedback were increased to take into account small actions on the handlebar. In functional terms, riders had to steer left to turn right and the more they maintained this initial steering angle, the greater the roll angle. When the initial steering movement was released so that the handlebar returned to its neutral position, the rolling angle was kept constant. When no force was applied on the handlebar following the initial steering movement, the handlebar turned in the direction of the bend and both the motorcycle and visual scene rolling angles were nullified.

\section{Procedure}

After being given an explanation of the basic principle of the experiment, participants signed the informed consent form and demographic data were collected. The full experiment was conducted in three parts, each of which followed the same experimental procedure and corresponded to a particular simulator configuration. First, the participants underwent a training session that consisted of two separate laps of the track in order to become familiar with the handling of the simulator. These two training runs were also used to familiarize the participants with the target speed $(90 \mathrm{~km} / \mathrm{h})$ as no speed feedback was given during data collection to avoid gaze deviations in the direction of the speedometer. To this aim, actual speed was not displayed, although verbal feedback was given to the participants when their speed fell below 
$70 \mathrm{~km} / \mathrm{h}$ or rose above $110 \mathrm{~km} / \mathrm{h}$. In this way, participants were free to control and adjust their

speed in accordance with the track geometry but had to remain in reasonable limits around $90 \mathrm{~km} / \mathrm{h}$. After the training session, participants were equipped with the eye tracker and the device was calibrated. The experiment proper consisted of riding two consecutive laps of the track, negotiating a total of 40 bends per simulator configuration. The order of presentation of the three simulator configurations was counterbalanced across participants. A 10-min break was observed between each experimental condition. Participants also completed the Simulator Sickness Questionnaire (SSQ; Kennedy, Lane, Berbaum, \& Lilienthal, 1993) and a validated French Canadian adaptation of the Presence Questionnaire (PQ) initially proposed by Witmer and Singer (1998; see Robillard, Bouchard, Renaud, \& Cournoyer, 2002). The SSQ was completed by the participants before and after each riding session, whilst the PQ was completed after each riding session. The whole experiment lasted approximately $1 \mathrm{~h} 30 \mathrm{~min}$.

\section{Data and statistical analysis}

Subjective measures. The PQ (Witmer \& Singer, 1998) consists of 24 items (two of them were removed because of irrelevance with respect to the simulator specifications) rated on a seven-point scale. The PQ assesses the degree of presence, i.e., the extent to which the user experiences the sense of "being there". In addition to offering a global score of presence, this instrument was chosen because it measures the participants' perception of system features and as such assesses the factors that influence presence (Schuemie, van der Straaten, Krijn \& van der Mast, 2001; Slater, 1999). The French Canadian adaptation gave rise to six subscales: realism ( 7 items), ability to act (4 items), interface quality (3 items), easiness to explore (3 items), self-rated performance ( 2 items), and auditory (3 items). The overall score and scores to each subscale were computed for each participant in each simulator configuration.

The SSQ consists of a checklist of 16 symptoms rated in terms of degree of severity (none, slight, moderate, severe), reflecting overall symptoms of sickness, with the highest 
possible score of 300. It also provides scores on three subscales (nausea, oculomotor disturbance, and disorientation). Using the weighted scoring procedure outlined by Kennedy et al. (1993), we calculated for each participant the total score reflecting the overall discomfort level and scores on the three subscales. These scores corresponded to the difference between the twice-repeated questionnaire (i.e., before and after the experimental session).

Behavioral measures. In order to investigate whether and how bend phases influence steering control and gaze behavior, riding and gaze data were brought together in three different sections of the bend: the approach phase, which corresponded to the last $50 \mathrm{~m}$ of straight road section before the start of the curve; the entry into the bend, which corresponded to the first half of each bend (i.e., up to the apex); and the bend exit, which corresponded to the second half of each bend (i.e., after the apex). The first $50 \mathrm{~m}$ of straight road section after the bend exit were excluded from the analysis. Bends in which a lane departure occurred were also excluded.

In order to express the lateral deviation of gaze and trajectory irrespective of the direction of the bend, the value of the measurements obtained in left bends was changed so that a negative value represented a deviation of position towards the left relative to the reference point, i.e., the center of the lane for the vehicle lateral position and the tangent point for the lateral deviation of gaze (see below). Conversely, a positive value represented a rightward deviation relative to the reference point.

With regard to riding behavior, the mean speed $(\mathrm{km} / \mathrm{h})$ and the mean and standard deviation of the lateral position with reference to the center of the lane $(\mathrm{cm})$ were calculated for each participant and each bend section. The number of lane departures was also computed but independently of the bend section (all departures occurred in the curved section of the bend). The mean speed and lateral position were used to report on the strategic aspects of curve negotiation while standard deviation of the lateral position and number of lane departure report- 
ed on the difficulty of steering. In addition, we analyzed how far into the bend the riders had

progressed before they cut across the center of their lane. As bends had different lengths, the distance at which this occurred was normalized and expressed as a percentage. The final $50 \mathrm{~m}$ of straight road sections was not used for this calculation. When riders cut the center of their lane at the time of the apex, they did so at the middle of the curve and a normalized distance of 50\% was obtained. This variable was assumed to give insight into riders' steering path strategy. The further they had progressed into a bend before they crossed the center of the lane, the more they adopted a "safety path". Finally, we computed the innermost position in each bend (i.e., the minimum distance from the inside edge line) to further examine the safety aspect of the expected steering path for each motorcycle simulator configuration.

With regard to visual behavior, the gaze resources competition for the anticipatory control of steering comes from the fact that when the gaze is directed toward far ahead distance, it is disengaged from the guidance steering level (Lehtonen et al., 2014; Wilkie et al., 2008). This suggests that analyzing the trade-off between guiding and look-ahead fixations may be a suitable way to capture gaze behavior as a function of simulator configuration. Whilst the analysis of this trade-off could be carried out by combining horizontal and vertical components of gaze, empirical evidence suggests the horizontal deviation of gaze is a robust marker of visual anticipation in bends. Wilkie et al. (2008) showed that cyclists negotiating slaloms previewed the next gate by making horizontal gaze switches of approximately $10^{\circ}$ while the vertical deviation was only $1-2^{\circ}$. Vansteenkiste et al. (2014) binned the cyclists' gaze location in a bend into either "lateral direction" or "depth" categories and showed the gaze dynamics was much more elaborate on the horizontal axis than on the vertical axis. In real driving conditions, Kandil, Rotter, and Lappe (2009) also noted that the vertical viewing angle remained relatively constant when the drivers looked at the road ahead, and Lehtonen et al. (2014) found that this was all the more the case when the fixations to the dashboard and 
mirrors were excluded. Based on these results, gaze behavior was assessed in the present study by determining the horizontal deviation of gaze relative to the Tangent Point (TP), that is to say the point where the direction of the inside edge line seems to reverse from the driver's viewpoint (Kandil et al., 2009; Land \& Lee, 1994; Wilson, Stephenson, Chattington, \& Marple-Horvat, 2007). More than a visual cue per se to track the visual scene and assess the road curvature at the sensorimotor level, the TP was used here as an objective dynamic spatial reference to analyze riders' gaze strategies. This was motivated by the fact that fixations in the vicinity of the TP capture a large proportion of guiding fixations whether they are future path fixations (e.g., Mars \& Navarro, 2012; Robertshaw \& Wilkie, 2008) or fixations to the tangent point itself (e.g., Kandil et al., 2009). To get an overall but fine-grained view of the gaze distribution, the visual scene was divided into 20 intervals of $1^{\circ}$ of angular deviation from the TP (from -10 to $+10^{\circ}$; see Figure 2 ). We then computed the proportion of gaze points falling within each interval. Gaze points that deviated more than $10^{\circ}$ in one direction or another were distributed between two additional classes (i.e., $<10^{\circ}$ or $>10^{\circ}$ ). The $+10^{\circ}$ deviation threshold from the TP was used as a measure of look-ahead fixations. Given the small but existing vertical dispersion, one should be aware that the chosen gaze analysis method precludes any conclusion regarding fixations on the TP per se. Data were finally brought together in the three bend sections under study.

Due to their nature, scores to the PQ (total and subscales), scores to the SSQ (total and subscales), and the number of lane departure were analyzed using a non-parametric Friedman's Test with the motorcycle simulator configuration as within-participant factor. In case of a significant effect, post hoc analysis was conducted with Wilcoxon signed-rank tests. As effect size cannot be calculated for Friedman's Test, we alternatively reported effect sizes as Cohen's $d$ for significant pairwise comparisons. Other variables were analyzed using repeated measures analyses of variance (ANOVAs). For the mean speed, the mean lateral position and 
the standard deviation of lateral position, two-way ANOVAs were conducted, with the simulator configuration and the bend section as within-participant factors. The distance at which the riders cut the centerline of the lane and the minimum deviation from the inside edge line during bend negotiation were analyzed with the motorcycle simulator configuration as the only within-participant factor. For gaze distribution, a three-way ANOVA was performed, with simulator configuration, bend section and angular deviation from the TP as withinparticipant factors. We conducted Mauchly's test of sphericity to determine whether the sphericity assumption was violated. In cases of violation, we used the Greenhouse-Geisser (GG) correction and modified degrees of freedom are reported. For each effect, partial eta-squared $\left(\eta_{\mathrm{p}}^{2}\right)$ was calculated to determine the proportion of total variability accounting for the effect. When necessary, significant effects were further examined using the Newman-Keuls post-hoc test. The initial significance level was set at 0.05 for all statistical analyses. However, HolmBonferroni correction for family-wise errors was respectively applied to subjective and behavioral measures to take into account the high number of tests run on the same dataset and reduce the risk of false positive.

\section{Results}

In the following section, the three motorcycle simulator configurations are labeled as: Static Dir_Steer, when the simulator was static and the control of steering relied on a direct steering model; Moving Dir_Steer, when the motion base of the simulator was activated and the steering control was direct; and Moving Rev_Steer, when the motion base of the simulator was activated and the steering control relied on a reverse model. We labeled the three sections of the bend as approach, entry and exit, as described earlier. The statistical results and corrected alpha level for the subjective and behavioral measures are summarized in Table 1 and 2 , respectively.

\section{Subjective measures}


Friedman's tests performed on the PQ total and subscale scores revealed significant differences between motorcycle simulator configurations on three subscales: realism, ability to act, and self-rated performance. Riders rated the Moving Rev_Steer configuration as being more realistic $(Z=3.33, p<.001, d=-1.05)$, although it was more difficult to control $(Z=2.97, p=.003, d=.90)$ and led to lower self-rated levels of performance $(Z=2.91$, $p=.004, d=.93)$ than the Static Dir_Steer configuration. The Moving Dir_Steer configuration did not differ significantly from the other two. Scores to the PQ are shown in Table 3.

Similar analyses were performed on total and subscale scores to the SSQ and did not reveal any significant differences between simulator configurations. The very low scores, shown in Table 3, reflect a very low level of discomfort if any among the participants who completed this study.

\section{Riding behavior}

Speed. The two-way repeated measures ANOVA yielded a significant main effect of bend section, due to a small but significant speed difference between bend entry $(94.4 \pm 0.85 \mathrm{~km} / \mathrm{h})$ and bend exit $(95 \pm 0.67 \mathrm{~km} / \mathrm{h})$. The interaction between simulator configuration and bend section was initially significant, with a slower speed in bend entry with the Moving Rev_Steer configuration, but it fell outside the conservative limits of the HolmBonferroni correction (see Table 2). Speed results are depicted for information in Figure 3.

Lateral position. The two-way repeated measures ANOVA on the mean distance from the center of the lane yielded a significant main effect of the motorcycle simulator configuration and bend section, and a significant interaction between these two factors (see statistical results in Table 2). On average, participants rode significantly further away from the center of their lane in the direction of the inner edge line with the Static Dir_Steer configuration $(26.1 \pm 50.1 \mathrm{~cm} ; p \mathrm{~s}<.001)$ than with the Moving Dir_Steer configuration $(14.1 \pm 53.5 \mathrm{~cm})$ and the Moving Rev_Steer configuration $(3.7 \pm 49.9 \mathrm{~cm})$, which also differed significantly 
from each other $(p<.001)$. As for the main effect of bend section (all $p$ s $<.001$ ), participants

had an overall steering strategy that consisted of steering from the outside edge of the lane $(-46.3 \pm 23.8 \mathrm{~cm}$ in the approach phase) to the inside edge when approaching the apex $(29.9 \pm 30.3 \mathrm{~cm}$ in the entry phase), before progressing in the inner part of the lane up to the exit $(60.3 \pm 22.5 \mathrm{~cm})$. The post-hoc test on the interaction between simulator configuration and bend section showed that, in the approach phase, participants deviated more towards the outside edge of their lane in the two motion-based configurations than in the static one ( $p$ s <.001). In the entry phase, all simulator configurations differed significantly (all $p s<.001)$ : in the Static Dir_Steer configuration, the average lateral position deviated towards the edge line, whilst riders maintained a relatively central position in the Moving Rev_Steer configuration. The Moving Dir_Steer condition lay between the two. In the exit phase, no significant differences were observed. The mean lateral position as a function of motorcycle simulator configuration and bend section is depicted in Figure 4. The average steering path for each motorcycle simulator configuration is shown for one bend (Length: $157 \mathrm{~m}$; Radius of curvature: $300 \mathrm{~m}$ ) in Figure 5.

The repeated measures ANOVA performed on the standard deviation of lateral position returned a main effect of the motorcycle simulator configuration and bend section, and a significant interaction between the two factors (see Table 2 for statistical results). The lateral position was more variable in the Moving Rev_Steer configuration $(29.5 \mathrm{~cm}$; $p$ s <.001) than in the two direct steering control configurations $(19.6$ and $20.9 \mathrm{~cm}$, in the Static and Moving Dir_Steer configurations, respectively). It was also more variable in the bend than during the approach $(16.1 \mathrm{~cm} ; p \mathrm{~s}<.001)$, and in the entry $(29 \mathrm{~cm})$ than in the exit phase $(25.1 \mathrm{~cm}$; $p<.01)$. As highlighted by the interaction, the effect of bend section was observed in all three motorcycle simulations (all $p$ s $<.001$ ), except that the standard deviation of lateral position in the Moving Rev_Steer configuration did not vary significantly between the entry and the exit 
phases of the bend $(p=.11)$. The interaction also showed that the lateral position was more

variable in the Moving Rev_Steer than in the two other simulator configurations in the three bend sections (all $p s<.001$; see Figure 6).

Lane departure. Friedman's test performed on the number of lane departures returned a main effect of motorcycle simulator configuration, due to a significant increase in the number of lane departures in the Moving Rev_Steer configuration compared with the direct steering control configurations $(Z s<3.41, p s<.001, d s<-1.20$; see Table 4). All departures occurred in the inner part of the turn.

Steering strategy. An analysis of the riders' progression in the bend (as a percentage of the bend) before they cut across the center of their lane revealed a main effect of the motorcycle simulator configuration. The three configurations all differed significantly from each other $(p s<.001)$. In all three configurations, the riders cut across the center of their lane before they reached the apex, but this occurred as expected later with the Moving Rev_Steer configuration (see Table 4 and Figure 5 for an illustration). In addition, riders rode closer to the inside edge line of the bend in the Moving Rev_Steer configuration compared with the two direct steering control model configurations (see Table 4 and Figure 5 for an illustration), but the difference fell shortly outside the conservative limits of the Holm-Bonferroni correction (see Table 2).

\section{Gaze behavior}

The $3 \times 3 \times 22$ repeated measures ANOVA on the proportion of gaze points revealed a significant main effect of angular deviation $\left(F(21,357)=71.2, p<.001, \eta_{\mathrm{p}}{ }^{2}=.81\right)$, and significant interactions between bend section and angular deviation $(F(42,714)=14.83$, $\left.p<.001, \eta_{\mathrm{p}}^{2}=.47\right)$, and between motorcycle simulator configuration and angular deviation $\left(F(42,714)=1.71, p<.01, \eta_{\mathrm{p}}^{2}=.09\right)$. The second-order interaction was not significant. 
Post-hoc tests for the main effect of angular deviation from the TP revealed significant increases in the proportion of gaze points, from $-2^{\circ}$ to $1^{\circ}$, with the peak of the distribution at $\left[0^{\circ} ; 1^{\circ}\left[(16.8 \%)\right.\right.$. The proportion of gaze points significantly decreased from $1^{\circ}$ to $4^{\circ}$. Moreover, $\left[9^{\circ} ; 10^{\circ}\right.$ [ and $\left[>10^{\circ}\right.$ [ differed significantly. This pattern of results suggests that riders did not direct their gaze a great deal towards the near section of the road $\left(6.1 \%\right.$ for $\left[-\infty^{\circ} ;-2^{\circ}[)\right.$. Conversely, most visual sampling was concentrated in the vicinity of the TP $(20.9 \%$ for [$2^{\circ} ; 0^{\circ}[)$ and even more so beyond the TP area in the direction of the bend exit ( $48.4 \%$ for $\left[0^{\circ} ; 4^{\circ}[\right.$. Some $5.8 \%$ of gaze points corresponded to look-ahead fixations into the far distance (above $10^{\circ}$ ). The post-hoc tests for the significant interaction between bend section and angular deviation revealed different gaze behavior as a function of bend section (Figure 7). A higher proportion of gaze was observed between $-3^{\circ}$ and $1^{\circ}$ of angular deviation in the approach phase (50.6\%) compared with the entry phase (31.3\%). Conversely, when entering the bends, the riders massively oriented their gaze toward the bend exit, with $82 \%$ of gaze directions oriented beyond the TP. The difference between the approach and entry phases was significant for all intervals between $2^{\circ}$ and $7^{\circ}$. No significant differences $(p=.07)$ were found in the proportion of look-ahead fixations between the approach and the entry phases. The gaze distribution in the exit phase mostly differed from the other sections by a lower number of gaze points directed into the far distance.

Gaze distribution also differed as a function of motorcycle simulator configuration (Figure 8). The interaction was mainly due to significant differences between the Moving Rev_Steer configuration and both Dir_Steer configurations. In the former, the riders looked more often between $-1^{\circ}$ and $1^{\circ}$ but less into the far distance $(p s<.001)$. The two Dir_Steer configurations did not differ significantly.

\section{Discussion}


The goal of this study was to examine the effects of motorcycle simulator configuration on riders' subjective experience, steering behavior and gaze distribution in a bend negotiation task. To this end, tilting the motorcycle mock-up and reverse steering, which are said to be two important contributors to the physical fidelity of motorcycle simulators (Benedetto et al., 2014; Crundall et al., 2014), were varied. Overall, the results revealed that roll tilt did not lead to significant changes in perceived realism, rider behavior or gaze sampling. With the introduction of reverse steering, perceived realism was higher and riders steered according to a safety-like strategy as hypothesized. However, steering control was more difficult as suggested by steering stability and gaze measures. The visual control of steering in motorcyclists is first discussed before the effects of various motorcycle simulator configurations on steering control are considered.

\section{Visual strategy for the control of steering in motorcyclists}

The visual control of steering has been extensively studied in car driving (for a discussion of theoretical models, see Lappi, 2014), and more recently in cycling (Vansteenkiste, Cardon, D'Hondt, Philippaerts, \& Lenoir, 2013; Vansteenkiste et al., 2014). However, very few studies have investigated the visual control of steering when riding a motorcycle. Two studies have examined riders' visual strategies by comparing the visual scanning behavior of experienced drivers and motorcyclists (Nagayama, Morita, Miura, Watanabem, \& Murakami, 1980; Tofield \& Wann, 2001). Recently, Lobjois et al. (2016b) found that riders' gaze deviated massively towards the bend exit, with more than $80 \%$ of gaze points beyond the TP, and the peak of distribution deviated by a visual angle of $2^{\circ}$ beyond the TP. In the present study, similar gaze behavior was observed, with $73 \%$ of gaze points directed beyond the TP over the entire bend. This figure is higher than would be the case in car driving simulator studies (for similar analyses performed on car drivers, see Mars \& Navarro, 2012). This greater anticipation in motorcyclists may be explained by a combination of high speed, unobstructed path- 
ways and open view conditions. Indeed, it has been shown that higher speeds result in more distant gaze behavior in cyclists (Vansteenkiste et al., 2013, 2014). Compared with car drivers, the gaze fixations of motorcyclists are more frequently located on the road surface, in order to detect any irregularities or hazards (Nagayama et al., 1980). Finally, the distance that is visible in a curve influences gaze behavior in such a way that drivers look further into the distance in open bends compared with closed bends (Kandil, Rotter, \& Lappe, 2010).

Results also showed that the peak of distribution was close to the TP. This visual behavior has often been seen as a strategy to make the tangent point the main visual input for the motor system (e.g., Kandil et al., 2009; Land \& Lee, 1994); however, Wilkie et al. (2010) and Kountouriotis, Floyd, Gardner, Merat, and Wilkie (2012) argued that this particular visual behavior was tightly linked to corner-cutting behavior and showed that gaze deviated from the TP, towards the road, when drivers had to maintain a middle or outer in-lane position. Alternatively, the asymmetry of gaze distribution, with a large proportion of gaze points directed beyond the TP, may suggest that motorcyclists look for a steering point further ahead. This visual behavior is compatible with the "look where you want to steer" hypothesis, according to which drivers look at the points on the road they wish to pass through (Wann \& Swapp, 2000; Wilkie \& Wann, 2003). This behavior would also be in line with the recommendations of advanced riding manuals (e.g., Ienatsch, 2003; Motorcycle Safety Foundation, 2004), which stress the importance of adopting relevant visual strategies to improve safety; in particular, they advocate that riders move their eyes from one waypoint to another as they progress (Wilkie et al., 2008).

The distribution of gaze points was also found to change as a function of bend section. When approaching the bend entry, more fixations were made in the direction of the lane center, supposedly on the roadway, suggesting that riders were anticipating their lateral position at the entry point of the bend. This is in line with Godthelp (1986) who suggested that at bend 
entrance, steering is based on anticipatory open-loop control (see also Vansteenkiste et al.,

2014, in cycling). In the first half of the bend, riders scanned the road well beyond the TP.

This gaze behavior may reflect trajectory planning and in particular the innermost position they intended to pass (which occurred in the second half of the bend). Overall, these results suggest that the riders' eyes were not locked on a unique steering point on the road ahead but oscillated between guiding and look-ahead fixations. They are furthermore in line with those of Lehtonen et al. $(2013,2014)$, who found that car drivers made look-ahead fixations throughout the whole curve. However, contrary to the findings for car driving, this type of fixation occurred in a similar proportion both in the approach and entry phases of the bend. These results may be explained by some steering path differences between driving a car and riding a motorcycle. Corner cutting is a common strategy in both car driving (Mars, 2008; Raw, Kountouriotis, Mon-Williams, \& Wilkie, 2012; Robertshaw \& Wilkie, 2008) and cycling (Vansteenkiste et al., 2014). The description of a classical steering path when negotiating bends made by Boer (1996) includes steering to the outer part of the lane before the curve starts in order to steer into the curve before its onset, and approaching the inner lane boundary around the apex. That motorcyclists maintained an outer position in their lane beyond the curve onset and, as such, steered into the curve later on may suggest that the transition between anticipatory open-loop and compensatory closed-loop control may be delayed in comparison with car driving. This may happen because the envelope of trajectory is much larger when motorcycling than when driving a car, and it is known that maintaining a particular steering path influences gaze behavior (e.g., Kountouriotis et al., 2012; Wilkie et al., 2010).

\section{Effects of motorcycle simulator configuration on steering and gaze behavior}

Results for the static configuration were very similar to those of Crundall et al. (2012) and Lobjois et al. (2016b), who showed a tendency among motorcyclists to steer into bends, adopting a 'racing line'. In the current study, participants seem to have favored progression 
since they crossed the centerline of their lane shortly after entering the bend and maintained

an inward position all along the curve section. In terms of gaze direction, participants had a high proportion of look-ahead fixations. This visual scanning of the road into the far distance suggests that this configuration placed low demands upon steering control (Lehtonen et al., 2012; Mars \& Navarro, 2012). This is supported by the low number of lane departures and high scores for the Self-rated Performance and Ability to Act subscales of the PQ. Similar results were found for the dynamic direct steering configuration. Although participants cut the centerline of the lane later when they moved gradually from the outer to the inner part of the road, they did not make substantial changes to their steering strategy. Participants had similar speed and innermost positioning in the bend to those found in the static configuration. They also looked frequently towards the bend exit. Coupled with the low number of lane departures, this configuration also placed low demands upon steering control. These results strongly suggest that riders steer into bends, adopting a 'racing line', in these two configurations. Thus, the introduction of physical tilt in the roll axis did not lead to significant changes in rider behavior, nor did it add to the perceived realism of the simulator. This is in contrast with the idea that motorcycle tilt is an important contributor to the riding experience in a simulator (Cossalter et al., 2010; Crundall et al., 2014; Lobjois et al., 2016a).

On the other hand, when reverse steering is introduced, changes at the subjective and behavioral level can be observed. The reverse steering configuration received the highest score on the Realism subscale of the PQ, which brings together items related to the authenticity of the virtual experience and its proximity to the real world. In addition, during an informal debriefing, 14 out of 18 participants ranked this condition as being first (the remaining 4 participants ranked the dynamic direct steering configuration as being first). At the behavioral level, speed reduction when entering the curve was marginally significant and participants maintained an outer position in the lane later on. According to Crundall et al. $(2012,2014)$, 
this particular behavior is aimed at providing a better entry angle and increased visibility

through the bend. As a consequence, riders crossed the center of their lane further away in the bend and then steered toward the inner part of the road. Taken together, these results are in accordance with the idea that riders in the reverse steering configuration may have adopted a safety path strategy, as described earlier (Crundall et al., 2012).

However, results highlighted difficulty in maintaining steering control in this configuration. First, riders judged it was the least easy to act on and to perform. Likewise, more lane departures were recorded and the lateral position was more variable in all three sections of the bend. Gaze behavior is also consistent with an increase in the steering demand: riders made fewer look-ahead fixations in favor of guiding fixations, suggesting that lateral control was more demanding in the reverse steering configuration. One potential explanation for these steering difficulties is related to the fact that reverse steering is an implicit strategy that is based on an internal model of motorcycle dynamics and riders are not always aware of using this control strategy (Belmonte, 2001; Fajans, 1999). In simulation, where the natural coupling between steering actions and the resultant gravito-inertial force is hindered, the internal model of steering control built through riding experience may have been at fault. As a result, riders may have voluntarily and consciously used reverse steering, leading to steering control difficulties. Indeed, the deleterious effect of supervision on performance has been reported on expert sensorimotor tasks. Logan and Crump (2009) proposed that expert manual activities rely on two control loops that operate in parallel. An external loop is in charge of the selection of actions, while an internal loop is in charge of controlling the execution of movements. These controlled and automatic processes are organized hierarchically in the form of encapsulation, as was shown by Fodor (1983). Paying attention to the movement execution means that the external loop supervises the input-output of the inner loop, which should only happen exceptionally in cases of error. Recently, Medeiros-Ward, Cooper, and Strayer (2014) reiterated 
this view in the context of driving to explain why cognitive distraction can lead to a deteriora-

tion of lateral control, but also sometimes to an improvement, depending on the presence or absence of external perturbations. In our case, the observed control difficulties may have been induced by the conscious supervision of reverse steering. Moreover, it has been shown that drivers have only limited conscious representation of the sequence of actions needed to steer their vehicle (Wallis, Chatziastros, \& Bülthoff, 2002). Specifically in the case of reverse steering, the leaning of the motorcycle serves to compensate for side forces. Thus, it may be that the riders, seeking to achieve a steady state in the bend, maintained their initial steering angle, whereas reverse steering should only be used to initiate leaning. This would explain the lane departures, all of which were consistent with overturning.

Finally, these results raise the question as to whether the safety path strategy is aimed at compensating for steering control difficulty or is representative of the recommended steering strategy for motorcycling despite these steering difficulties. Indeed, Raw et al. (2012) showed that older drivers reduced corner-cutting behavior by adopting a "middle-of-the-road" strategy used to compensate for age-related steering control difficulties. The present steering behavior with the reverse steering configuration is however not consistent with a "middle-ofthe-road" strategy: riders deviated more toward the outer part of their lane when they approached the bend and deviated toward the inside edge line when they negotiated the second half of the bend. If riders had intended to take a safer steering path, they would have preferentially increased their safety margins to avoid lane departure.

\section{Conclusion}

With respect to motorcyclists' gaze behavior in a bend negotiation task, results showed that the overall distribution between guiding and look-ahead fixations did resemble that of car drivers (e.g., Mars \& Navarro, 2012) or cyclists (e.g., Vansteenkiste et al., 2014); however, the gaze behavior of motorcyclists was notably characterized by anticipation. This 
could be explained by a combination of high speed, unobstructed pathways and open view clists on closed bends to get a more general picture of visual and motor control when riding. It would also be a way to test whether the difference observed between the direct and reverse control configuration generalize to other types of road geometry.

Whilst the introduction of inertially specified roll tilt did not lead to changes in perceived realism, riding behavior or gaze sampling, steering control strategy did significantly influence the results. With the direct steering control strategy, riders took a racing path and scanned the road far in advance. By way of contrast, when reverse steering was implemented, riders steered a trajectory closer to the safety path recommended in training manuals. Reverse steering also received the highest realism score. However, the control of steering was seen to be more difficult, as revealed by a larger number of lane departures and a change in the tradeoff between guiding and look-ahead fixations. While researchers' interest in VR systems to study human movement control is relatively well established (e.g., Baurès, Benguigui, Amorim, \& Hecht, 2009; Lepecq, Bringoux, Pergandi, Coyle, \& Mestre, 2009; Zaal \& Bootsma, 2011), our results confirm previous findings that show the influence of immersive and interactive characteristics of VR systems on how humans behave or perform (e.g., Lobjois et al., 2016b; Morice et al., 2008; Grechkin et al., 2014). While a number of studies have paid attention to simulator characteristics to improve physical fidelity (e.g., Chatziastros, Wallis, \& Bülthoff, 1999; Jamson \& Jamson, 2010; Klüver et al., 2016), it is acknowledged that behavioral validity is more important than physical validity (Klüver et al., 2016; Pinto et al., 2008). This is because the strict duplication of reality is impossible to obtain in simulated driving. In addition, a high level of physical fidelity is not always required to achieve good levels of behavioral fidelity (Pinto et al., 2008). In the present study, increasing physical fidelity was shown to improve subjective and behavioral validity (see also Klüver et al., 2016). But these 
improvements do not necessarily prevent from some drawbacks. These results thus suggest

that the effects of VR systems on users are also to be investigated at the level of psychological fidelity, i.e., at the level of the underlying processes. Finally, it is obvious that on-road measures of rider behavior may help in validating the results of our study. This would favor the use of motorcycle simulators implementing reverse steering in order to study rider behavior or to offer rider training in a safe and convenient environment (Vidotto, Tagliabue, \& Tira, 2015). 


\section{References}

Alm, H., 1995. Driving simulator as research tools: a validation study based on the VTI Driving Simulator. Drive II V2065: GEM Validation Studies. Reference GEM/TR/TRC/MK950327, VTI, Linköping, Sweden.

Arioui, H., Nehaoua, L., Hima, S., Séguy, N., \& Espié, S. (2010). Mechatronics design and modeling of a motorcycle riding simulator. IEEE Transactions on Mechatronics, 15, 805-818. doi:10.1109/TMECH.2009.2035499

Baurès, R., Benguigui, N., Amorim, M-A., \& Hecht, H. (2009). Intercepting real and simulated falling objects: What is the difference? Journal of Neuroscience Methods, 184, 4853. doi:10.1016/j.jneumeth.2009.07.022

Belmonte, J-P. (2001). Le contrebraquage en conduite motocycliste. Turbopress Inc. Retrieved from: http://www.arpenter.net/bepecaser/contrebraquage.pdf

Benedetto, S., Lobjois, R., Faure, V., Dang, N.-T., Pedrotti, M., \& Caro, S. (2014). A comparison of immersive and interactive motorcycle simulator configurations. Transportation Research Part F: Traffic Psychology and Behaviour, 23, 88-100. doi:10.1016/j.trf.2013.12.020

Blaauw, G. J. (1982). Driving experience and task demands in simulator and instrumented car: A validation study. Human Factors, 24, 473-486. doi:10.1177/001872088202400408

Boer, E. R. (1996). Tangent point oriented curve negotiation. Proceedings of the Intelligent Vehicles Symposium, IEEE Conference 617:7-12. doi:10.1109/IVS.1996.566341

Borghini, G., Astolfi, L., Vecchiato, G., Mattia, D., \& Babiloni, F. (2014). Measuring neurophysiological signals in aircraft pilots and car drivers for the assessment of mental workload, fatigue and drowsiness. Neuroscience \& Biobehavioral Reviews, 44, 58-75. doi:10.1016/j.neubiorev.2012.10.003

Chatziastros, A., Wallis, G. M., \& Bülthoff, H. H. (1999). The effect of field of view and surface texture on driver steering performance. In A. G. Gale (Ed.), Vision in Vehicles VII (pp. 253-259). Elsevier, Amsterdam.

Clarke, D. D., Ward, P., Bartle, C., \& Truman, W. (2007). The role of motorcyclists and other driver behavior in two types of serious accidents in the UK. Accident Analysis \& Prevention, 39, 974-981. doi:10.1016/j.aap.2007.01.002

Cossalter, V., Lot, R., \& Rota, S. (2010). Objective and subjective evaluation of advanced motorcycle riding simulator. European Transport Research Review, 2, 223-233. doi:10.1007/s 12544-010-0041-2

Crundall, E., Crundall, D., \& Stedmon, A. W. (2012). Negotiating left-hand and right-hand bends: A motorcycle simulator study to investigate experiential and behavior differences across rider groups. PLoS One 7 (1), e29978. doi:10.1371/journal.pone.0029978 
Crundall, D., Stedmon, A. W., Crundall, E., \& Saikayasit, R. (2014). The role of experience and advanced training on performance in a motorcycle simulator. Accident Analysis \& Prevention, 73, 81-90. doi:10.1016/j.aap.2014.08.009

Crundall, E., Stedmon, A. W., Saikayasit, R., \& Crundall, D. (2013). A simulator study investigating how motorcyclists approach side-road hazards. Accident Analysis \& Prevention, 51, 42-50. doi:10.1016/j.aap.2012.10.017

de Waard, D. (1996). The Measurement of Drivers' Mental Workload. Traffic Research Center, Groningen University, Netherlands.

Di Stasi, L., Álvarez-Valbuena, V., Cañas, J. J., Maldonado, A., Catena, A., Antolí, A., \& Candido, A. (2009). Risk behaviour and mental workload: Multimodal assessment techniques applied to motorbike riding simulation. Transportation Research Part F: Traffic Psychology and Behaviour, 12, 361-370. doi:10.1016/j.trf.2009.02.004

Diels, C., Robbins, R., \& Reed, N. (2011). Behavioural validation of the TRL driving simulator DigiCar: phase 1 - Speed choice. In L. Dorn (Ed.), Driver Behaviour and Training, vol. 5 (pp. 429-446). Farnham: Ashgate.

Donges, E. (1978). A two-level model of driver steering behaviour. Human Factors, 20, 691707. doi:10.1177/001872087802000607

Fajans, J. (1999). Steering in bicycles and motorcycles. American Journal of Physic, 68, 654659. doi:10.1119/1.19504

Fodor, J. A. (1983). The modularity of mind: An essay on faculty psychology. MIT Press.

Frissen, I., \& Mars, F. (2014). The effect of visual degradation on anticipatory and compensatory steering control. Quarterly Journal of Experimental Psychology, 67, 499-507. doi:10.1080/17470218.2013.819518

Godthelp, H. (1986). Vehicle control during curve driving. Human Factors, 28, 211-221. doi:10.1177/001872088602800209

Grechkin, T. Y., Plumert, J. M., \& Kearney, J. K. (2014). Dynamic affordances in embodied interactive systems: The role of display and mode of locomotion. IEEE Transactions on Visualization and Computer Graphics, 20, 596-605. doi: 10.1109/TVCG.2014.18

Huth, V., Biral, F., Martín, O., \& Lot, R. (2012). Comparison of two warning concepts of an intelligent curve warning system for motorcyclists in a simulator study. Accident Analysis and Prevention, 44, 118-125. doi:10.1016/j.aap.2011.04.023

Ienatsch, N. (2003). Sport riding techniques: How to develop real world skills for speed, safety and confidence on the street and track. Phoenix, AZ: David Bull.

Jamson, S. L., \& Jamson, A. H. (2010). The validity of a low-cost simulator for the assessment of the effects of in-vehicle information systems. Safety Science, 48, 1477-1483. doi: 10.1016/j.ssci.2010.07.008

Kandil, F. I., Rotter, A., \& Lappe, M. (2009). Driving is smoother and more stable when using the tangent point. Journal of Vision, 9(1):11, 1-11. doi:10.1167/9.1.11 
Kandil, F. I., Rotter, A., \& Lappe, M. (2010). Car drivers attend to different gaze targets when negotiating closed vs. open bends. Journal of Vision, 10(4):24, 1-11. doi:10.1167/10.4.24

Kennedy, R. S., Lane, N. E., Berbaum, K. S., \& Lilienthal, M. G. (1993). Simulator Sickness Questionnaire: An enhanced method for quantifying simulator sickness. The International Journal of Aviation Psychology, 3, 203-220. doi:10.1207/s15327108ijap0303_3

Klüver, M., Herrigel, C., Heinrich, C., Schöner, H.-P., \& Hecht, H. (2016). The behavioral validity of dual-task driving performance in fixed and moving base driving simulators. Transportation Research Part F: Traffic Psychology and Behaviour, 37, 78-96. doi:10.1016/j.trf.2015.12.005

Kountouriotis, G. K., Floyd, R. C., Gardner, P. H., Merat, N., \& Wilkie, R. M. (2012). The role of gaze and road edge information during high-speed locomotion. Journal of Experimental Psychology: Human Perception and Performance, 38, 687-702. doi:10.1037/a0026123

Land, M., \& Horwood, J. (1995). Which parts of the road guide steering? Nature, 377, 339340. doi:10.1038/377339a0

Land, M. F., \& Lee, D. N. (1994). Where we look when we steer. Nature, 369, 742-744. doi:10.1038/369742a0

Lappi, O. (2014). Future path and tangent point models in the visual control of locomotion in curve driving. Journal of Vision, 14(21), 1-22. doi:10.1167/14.12.21

Lehtonen, E., Lappi, O., \& Summala, H. (2012). Anticipatory eye movements when approaching a curve on a rural road depend on working memory load. Transportation Research Part F: Traffic Psychology and Behavior, 15, 369-377. doi:10.1016/j.trf.2011.08.007

Lehtonen, E., Lappi, O., Koirikivi, I., \& Summala, H. (2014). Effect of driving experience on anticipatory look-ahead fixations in real curve driving. Accident Analysis and Prevention, 70, 195-208. doi:10.1016/j.aap.2014.04.002

Lehtonen, E., Lappi, O., Kotkanen, H., \& Summala, H. (2013). Look-ahead fixations in curve driving. Ergonomics, 56, 34-44. doi:10.1080/00140139.2012.739205

Lepecq, J-C., Bringoux, L., Pergandi, J-M., Coyle, T., \& Mestre, D. (2009). Afforded actions as a behavioral assessment of physical presence in virtual environments. Virtual Reality, 13, 141-151. doi: 10.1007/s10055-009-0118-1

Liu, C. C., Hosking, S. G., \& Lenné, M. G. (2009). Hazard perception abilities of experienced and novice motorcyclists: An interactive simulator experiment. Transportation Research Part F: Traffic Psychology and Behaviour, 12, 325-334. doi:10.1016/j.trf.2009.04.003

Lobjois, R., Dagonneau, V., \& Isableu, B. (2016a). The contribution of visual and proprioceptive information to the perception of leaning in a dynamic motorcycle simulator. Ergonomics, 59, 1428-1441. doi:10.1080/00140139.2016.1149229 
Lobjois, R., Siegler, I. A., \& Mars, F. (2016b). Effects of visual roll on steering control and gaze behavior in a motorcycle simulator. Transportation Research: Traffic Psychology and Behavior, 38, 55-66. doi:10.1016/j.trf.2016.01.002

Logan, G. D., \& Crump, M. J. C. (2009). The left hand doesn't know what the right hand is doing: the disruptive effects of attention to the hands in skilled typewriting. Psychological Science, 20, 1296-1300. doi:10.1111/j.1467-9280.2009.02442.x

Malaterre, G., \& Fréchaux, J. (2001). Étude de la validité des simulateurs de conduite par comparaison de tâches réalisées en situation réelle et en simulation. In V. Cavallo \& C. Berthelon (Eds.), Facteurs perceptifs dans les activités de transport (pp. 149-156). Arcueil, France: INRETS.

Mars, F. (2008). Driving around bends with manipulated eye-steering coordination. Journal of Vision, 8(11), 1-11. doi:10.1167/8.11.10

Mars, F., \& Navarro, J. (2012). Where we look when we drive with or without active steering wheel control. PLoS ONE, 7(8), e43858. doi:10.1371/journal.pone.0043858

Mars, F., Saleh, L., Chevrel, P., Claveau, F., \& Lafay, J. F. (2011). Modeling the visual and motor control of steering with an eye to shared control automation. In Proceedings of the 55th Annual Meeting of the Human Factors and Ergonomics Society (pp. 14221426). Las Vegas, NV.

Medeiros-Ward, N., Cooper, J. M., \& Strayer, D. L. (2014). Hierarchical control and driving. Journal of Experimental Psychology: General, 143, 953-958. doi:10.1037/a0035097

Mehler, B., Reimer, B., Coughlin, J. F., \& Dusek J. A. (2009). Impact of incremental increases in cognitive workload on physiological arousal and performance in young adult drivers. Transportation Research Record, 2138, 6-12. doi:10.3141/2138-02

Morice, A. H. P, Siegler I. A., \& Bardy, B. G. (2008). Action-perception patterns in virtual ball-bouncing: Combating system latency and tracking functional validity. Journal of Neuroscience Methods, 169, 255-266. doi:10.1016/j.jneumeth.2007.11.020

Motorcycle Safety Foundation (2004). The motorcycle safety foundation's guide to motorcycling excellence: Skills, knowledge, and strategies for riding right. Osceola (WI): Motorbooks International.

Nagayama, Y, Morita, T., Miura, T., Watanabem, J., \& Murakami, N. (1980). Motorcyclists' visual scanning pattern in comparison with automobile drivers. Society of Automotive Engineers (SAE), Technical Paper 790262. Society of Automotive Engineers, Warrendale, $\mathrm{PA}$.

National Highway Traffic Safety Administration - NHTSA (2016). 2015 motor vehicle crashes: Overview. Research Note, U.S. Department of Transportation, August 2016.

Nehaoua, L., Arioui, H., \& Mammar, S. (2013). Motorcycle riding simulator: How to estimate robustly the rider's action. IEEE Transactions on Vehicular Technology, 62, 80-88. doi:10.1109/TVT.2012.2215052 
Observatoire National Interministériel de Sécurité Routière - ONISR (2007). Les motocyclettes et la sécurité routière en France en 2005. La Documentation Française, Paris.

Observatoire National Interministériel de Sécurité Routière - ONISR (2010). La sécurité routière en France: bilan de l'année 2009. Paris: La Documentation Française.

Organization for Economic Co-operation and Development - OECD/ITF (2015). Improving safety for motorcycle, scooter and moped riders. OECD Publishing, Paris. doi:10.1787/9789282107942-en/

Pinto, M., Cavallo, V., \& Ohlmann, T. (2008). The development of driving simulators: Toward a multisensory solution. Le Travail Humain, 71, 62-95. doi:10.3917/th.711.0062

Raw, R. K., Kountouriotis, G. K., Mon-Williams, M., \& Wilkie, R.M. (2012). Movement control in older adults: Does old age mean middle of the road? Journal of Experimental Psychology: Human Perception and Performance, 38, 735-745. doi:10.1037/a0026568

Recarte, M. A., \& Nunes, L. M. (2003). Mental workload while driving: Effects on visual search, discrimination, and decision making. Journal of Experimental Psychology: Applied, 9(2), 119-137. doi:10.1037/1076-898X.9.2.119

Reimer, B., \& Mehler, B. (2011). The impact of cognitive workload on physiological arousal in young adult drivers: A field study and simulation validation. Ergonomics, 54, 932942. doi:10.1080/00140139.2011.604431

Robertshaw, K. D., \& Wilkie, R. M. (2008). Does gaze influence steering around a bend? Journal of Vision, 8(4), 1-13. doi:10.1167/8.4.18

Robillard, G., Bouchard, S., Renaud, P., \& Cournoyer, L. G. (2002). Validation canadiennefrançaise de deux mesures importantes en réalité virtuelle: 1'Immersive Tendencies Questionnaire et le Presence Questionnaire. Affiche présentée au $25^{\text {ième }}$ congrès de la Société Québécoise pour la Recherche en Psychologie (SQRP), Trois-Rivières, 1-3 novembre.

Salvucci, D., \& Gray, R. (2004). A two-point visual control model of steering. Perception, 33, 1233-1248. doi:10.1068/p5343

Schuemie, M. J., van der Straaten, P., Krijn, M., \& van der Mast, C. A. P. G. (2001). Research on presence in virtual reality. Presence: Teleoperators and Virtual Environments, 4, 183-201. doi:10.1089/109493101300117884

Slater, M. (1999). Measuring presence: A response to the Witmer and Singer presence questionnaire. Presence: Teleoperators and Virtual Environments, 8, 560-565. doi:10.1162/105474699566477

Slater, M. (2009). Place illusion and plausibility can lead to realistic behaviour in immersive virtual environments. Philosophical Transactions of the Royal Society of London B: Biological Sciences, 364(1535):3549-3557. doi: 10.1098/rstb.2009.0138

Stedmon, A. W., Hasseldine, B., Rice, D., Young, M., Markham, S., Hancox, M., Brickwell, E., \& Noble, J. (2011). 'MotorcycleSim': An evaluation of rider interaction with an 
innovative motorcycle simulator. The Computer Journal, 54, 1010-1025. doi:10.1093/comjnl/bxp071

Summala, H., Nieminen, T., \& Punto, M. (1996). Maintaining lane position with peripheral vision during in-vehicle tasks. Human Factors, 38, 442-451. doi:10.1518/001872096778701944

Tofield, M. I., \& Wann, J. P. (2001). Do motorcyclists make better car drivers? In: Proceedings of Psychological Post-graduate Affairs Group conference, Glasgow, Scotland.

Vansteenkiste, P., Cardon, G., D'Hondt, E., Philippaerts, R., \& Lenoir, M. (2013). The visual control of bicycle steering: The effects of speed and path width. Accident Analysis \& Prevention, 51, 222-227. doi:10.1016/j.aap.2012.11.025

Vansteenkiste, P., Van Hamme, D., Veelaert, P., Philippaerts, R., Cardon, G., \& Lenoir, M. (2014). Cycling around a curve: The effect of cycling speed on steering and gaze behavior. PLoS ONE 9(7): e102792. doi:10.1371/journal.pone.0102792

Vidotto, G., Tagliabue, M., \& Tira, M. D. (2015). Long-lasting virtual motorcycle-riding trainer effectiveness. Frontiers in Psychology 6-1653. doi:10.3389/fpsyg.2015.01653

Wallis, G., Chatziastros, A., \& Bülthoff, H. (2002). An unexpected role for visual feedback in vehicle steering control. Current Biology, 12, 295-299. doi: 10.1016/s09609822(02)00685-1

Wann, J. P., \& Swapp, D. K. (2000). Why you should look where you are going. Nature Neuroscience, 3, 647-648. doi:10.1038/76602

Wilkie, R. M., Kountouriotis, G. K., Merat, N., \& Wann, J. P. (2010). Using vision to control locomotion: Looking where you want to go. Experimental Brain Research, 204, 539547. doi:10.1007/s00221-010-2321-4

Wilkie, R. M., \& Wann, J. P. (2003). Eye-movements aid the control of locomotion. Journal of Vision, 3, 677-684. doi:10.1167/3.11.3

Wilkie, R. M., Wann, J. P., \& Allison, R. S. (2008). Active gaze, visual look-ahead, and locomotor control. Journal of Experimental Psychology: Human Perception and Performance, 34, 1150-1164. doi:10.1037/0096-1523.34.5.1150

Wilson, M., Stephenson, S., Chattington, M., \& Marple-Horvat, D. E. (2007). Eye movements coordinated with steering benefit performance even when vision is denied. Experimental Brain Research, 176, 397-412. doi:10.1007/s00221-006-0623-3

Witmer, B. G., \& Singer, M. J. (1998). Measuring presence in virtual environments: A presence questionnaire. Presence: Teleoperators and virtual environments, 7, 225-240. doi:10.1162/105474698565686

Zaal, F. T. J. M., \& Bootsma, R. J. (2011). Virtual reality as a tool for the study of perception-action: The case of running to catch fly balls. Presence, 20, 93-103. doi:10.1162/pres_a_00037 
Table 1

1

Statistical results for the subjective measures (PQ and SSQ scores)

\begin{tabular}{lcccc}
\cline { 2 - 5 } & \multicolumn{4}{c}{ Simulator Configuration } \\
\cline { 2 - 5 } & $\chi^{2}$ & $\mathrm{df}$ & $\mathrm{p}$ & Corrected $\alpha$ level \\
\hline PQ Total & 1.03 & 2 & .60 & .02 \\
Realism & 10.17 & 2 & $.006^{*}$ & .01 \\
Ability to Act & 14.85 & 2 & $.0006^{*}$ & .007 \\
Interface Quality & .30 & 2 & .86 & .03 \\
Easiness to Explore & 4.98 & 2 & .08 & .012 \\
Self-rated Performance & 13.21 & 2 & $.001^{*}$ & .008 \\
Auditory & .19 & 2 & .91 & .05 \\
\hline SSQ Total & 5.24 & 2 & .07 & - \\
Nausea & 1.22 & 2 & .54 & - \\
Oculomotor Disturbance & 1.56 & 2 & .45 & - \\
Disorientation & 1.08 & 2 & .58 & - \\
\hline
\end{tabular}

*: Significant differences after Holm-Bonferroni correction. 
Table 2

Statistical results for the riding behavior measures (speed, lateral position, lane departure, and steering strategy).

\begin{tabular}{|c|c|c|c|c|c|c|c|c|c|c|c|c|c|c|c|}
\hline & \multicolumn{5}{|c|}{ Simulator Configuration } & \multicolumn{5}{|c|}{ Bend Section } & \multicolumn{5}{|c|}{ Simulator Configuration $\mathrm{x}$ Bend Section } \\
\hline & Statistic & df & $\mathrm{p}$ & $\eta_{\mathrm{p}}^{2}$ & $\begin{array}{c}\text { Corrected } \\
\alpha \text { level } \\
\end{array}$ & Statistic & df & $\mathrm{p}$ & $\eta_{\mathrm{p}}^{2}$ & $\begin{array}{c}\text { Corrected } \\
\alpha \text { level } \\
\end{array}$ & Statistic & df & $\mathrm{p}$ & $\eta_{\mathrm{p}}^{2}$ & $\begin{array}{c}\text { Corrected } \\
\alpha \text { level } \\
\end{array}$ \\
\hline Speed & $.03^{\mathrm{a}}$ & 2,34 & .97 & - & .05 & $5.65^{\mathrm{a}}$ & $1.65,28.15$ & $.012 *$ & .25 & .0125 & $4.20^{\mathrm{a}}$ & $1.86,31.68$ & .026 & .20 & .016 \\
\hline $\begin{array}{l}\text { Mean Lateral } \\
\text { Position }\end{array}$ & $35.41^{\mathrm{a}}$ & 2,34 & $.001 *$ & .68 & .0062 & $258.59^{\mathrm{a}}$ & 2,34 & $<.001 *$ & .94 & .0045 & $10.79^{\mathrm{a}}$ & $1.92,32.64$ & $<.001 *$ & .39 & .007 \\
\hline $\begin{array}{l}\text { Standard Devia- } \\
\text { tion of Lateral } \\
\text { Position }\end{array}$ & $38.62^{\mathrm{a}}$ & $1.45,24.79$ & $.001 *$ & .70 & .005 & $53.04^{\mathrm{a}}$ & 2,34 & $<.001 *$ & .78 & .0055 & $10.48^{a}$ & 4,68 & $<.001 *$ & .38 & .008 \\
\hline Lane Departure & $24.25^{\mathrm{b}}$ & 2 & $.001 *$ & - & .01 & - & - & - & - & - & - & - & - & - & - \\
\hline $\begin{array}{l}\% \text { of the bend } \\
\text { where the riders } \\
\text { cut the center of } \\
\text { the lane }\end{array}$ & $83.15^{\mathrm{a}}$ & 2,34 & $.001 *$ & .83 & .0041 & - & - & - & - & - & - & - & - & - & - \\
\hline $\begin{array}{l}\text { Innermost Lateral } \\
\text { Position }\end{array}$ & $3.94^{\mathrm{a}}$ & 2,34 & .028 & .19 & .025 & - & - & - & - & - & - & - & - & - & - \\
\hline
\end{tabular}

${ }^{\mathrm{a}}: F$ statistic. $^{\mathrm{b}}: \chi^{2}$ statistic. $*$ : Significant differences after Holm-Bonferroni correction. 
Running head: Steering path and visual control of steering in motorcycle simulators

Table 3

1

Overall and subscale scores to the Simulator Sickness and Presence Questionnaires (SDs are in parentheses).

\begin{tabular}{lccc}
\cline { 2 - 4 } & \multicolumn{3}{c}{ Motorcycle Simulator Configuration } \\
\cline { 2 - 4 } & Static Dir_Steer & Moving Dir_Steer & Moving Rev_Steer \\
\hline SSQ & $0.21(6.1)$ & $4.99(12.9)$ & $1.45(5.8)$ \\
Nausea & $0.00(4.6)$ & $3.18(12.7)$ & $1.06(5.6)$ \\
Oculomotor & $0.00(8.6)$ & $4.21(10.1)$ & $1.68(7.6)$ \\
Disorientation & $0.77(3.3)$ & $3.87(14.2)$ & $0.77(7.5)$ \\
\hline PQ (154) & $118.6(15.5)$ & $118.3(18.9)$ & $116.5(16.7)$ \\
Realism (49) & $31.4(7.7)$ & $34.1(8.0)$ & $36.8(5.9)$ \\
Ability to act (28) & $25.0(2.7)$ & $23.9(3.3)$ & $22.3(3.5)$ \\
Interface Quality (21) & $17.2(3.0)$ & $16.6(3.2)$ & $16.2(3.1)$ \\
Easiness to explore (21) & $16.0(3.6)$ & $15.2(3.8)$ & $14.6(3.9)$ \\
Self-rated performance (14) & $12.5(1.5)$ & $11.3(2.6)$ & $10.0(2.6)$ \\
Auditory (21) & $16.6(3.2)$ & $16.6(3.3)$ & $16.7(3.6)$ \\
\hline
\end{tabular}

Note. SSQ: Simulator Sickness Questionnaire; PQ: Presence Questionnaire. The highest possible score for each subscale of the PQ is indicated in parentheses. 
Table 4

1

Lane departure data (mean number) and steering strategy data (mean) as a function of the motorcycle simulator configuration (SDs are in parentheses).

\begin{tabular}{lccc}
\cline { 2 - 4 } & \multicolumn{3}{c}{ Motorcycle Simulator Configuration } \\
\cline { 2 - 4 } & $\begin{array}{c}\text { Static } \\
\text { Dir_Steer }\end{array}$ & $\begin{array}{c}\text { Moving } \\
\text { Dir_Steer }\end{array}$ & $\begin{array}{c}\text { Moving } \\
\text { Rev_Steer }\end{array}$ \\
\hline Lane departure & 0.5 & 0.4 & 3.2 \\
Percentage of the bend where the riders cut the center & $(0.47)$ & $(0.61)$ & $(2.5)$ \\
of the lane & 10.5 & 21.1 & 30.7 \\
Innermost lateral position in the bend (cm) & $(8.2)$ & $(13.2)$ & $(10.5)$ \\
& 76 & 77 & 63 \\
\end{tabular}


1

2

3

4

5

6

7

8

9

10

11

12

13

14

15

16

17

18

19

20

21

22

23

24

25

26

27

28

29

30

31

32

33

34

35

36

37

38

39

40

41

42

43

44

45

46

47

48

49

50

51

52

53

54

55

56

57

58

59

60

61

62

63

64

65

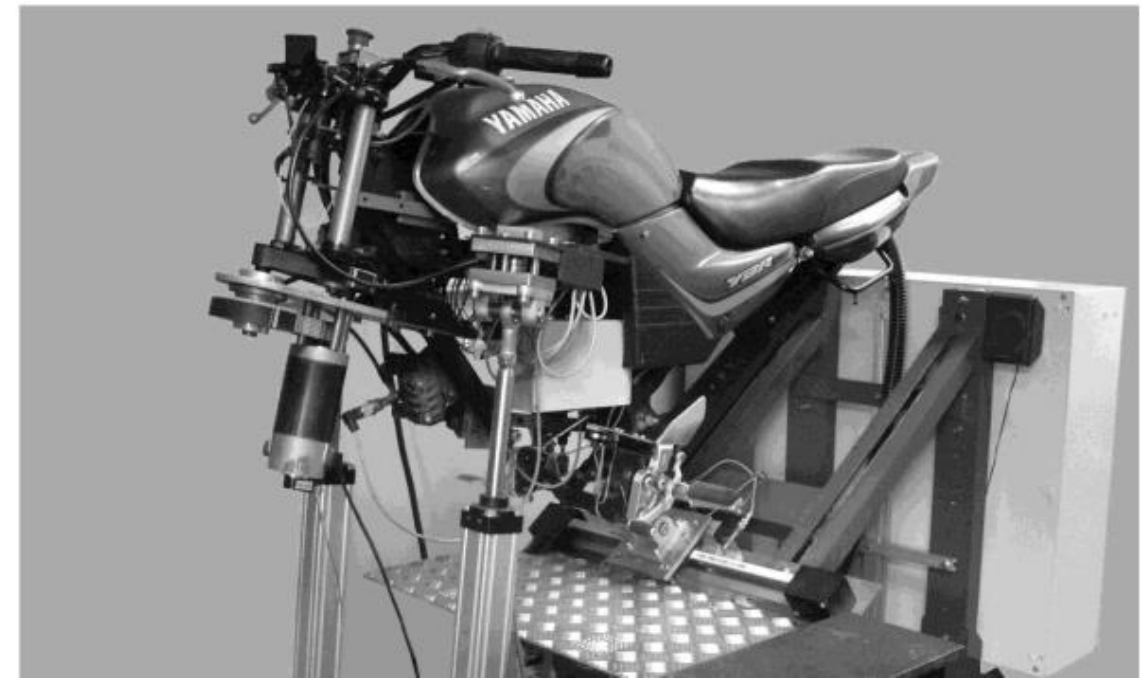

Figure 1. Motion-based motorcycle simulator. 
1

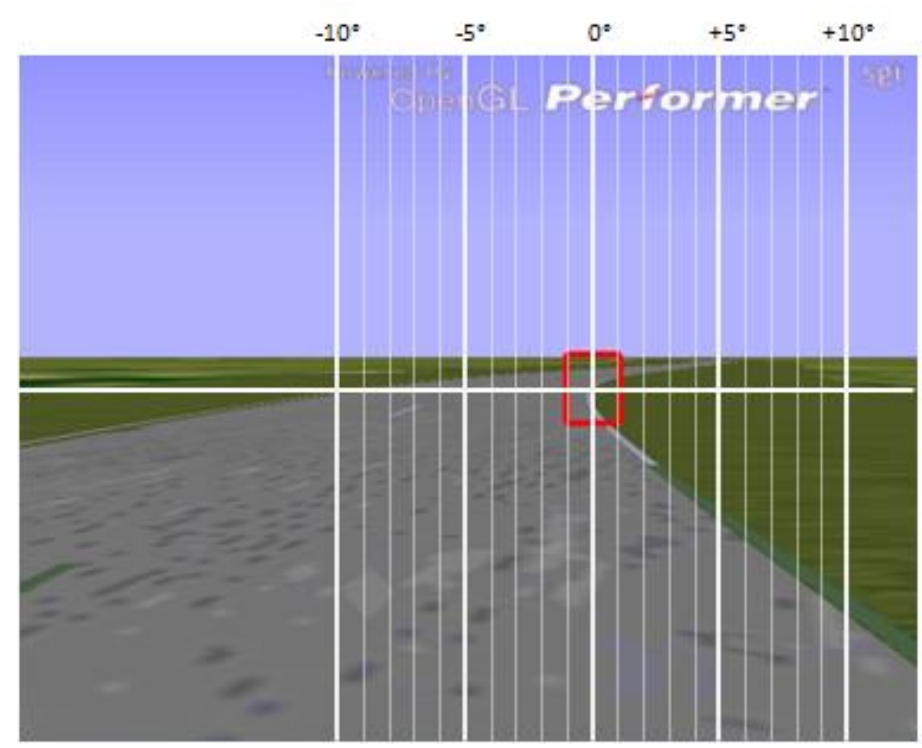

Figure 2. Division of the visual scene into $1^{\circ}$ intervals on the horizontal axis. Each angular deviation has the tangent point as its origin. Gaze points that fall beyond $10^{\circ}$ in one direction or another were divided into two additional classes (i.e., $<10^{\circ}$ or $>10^{\circ}$ ). Negative angular deviation means that gaze is directed toward the road whilst positive angular deviation means that riders are looking further ahead from the tangent point, i.e., in the direction of the bend exit. 
1

2

3

4

5

6

7

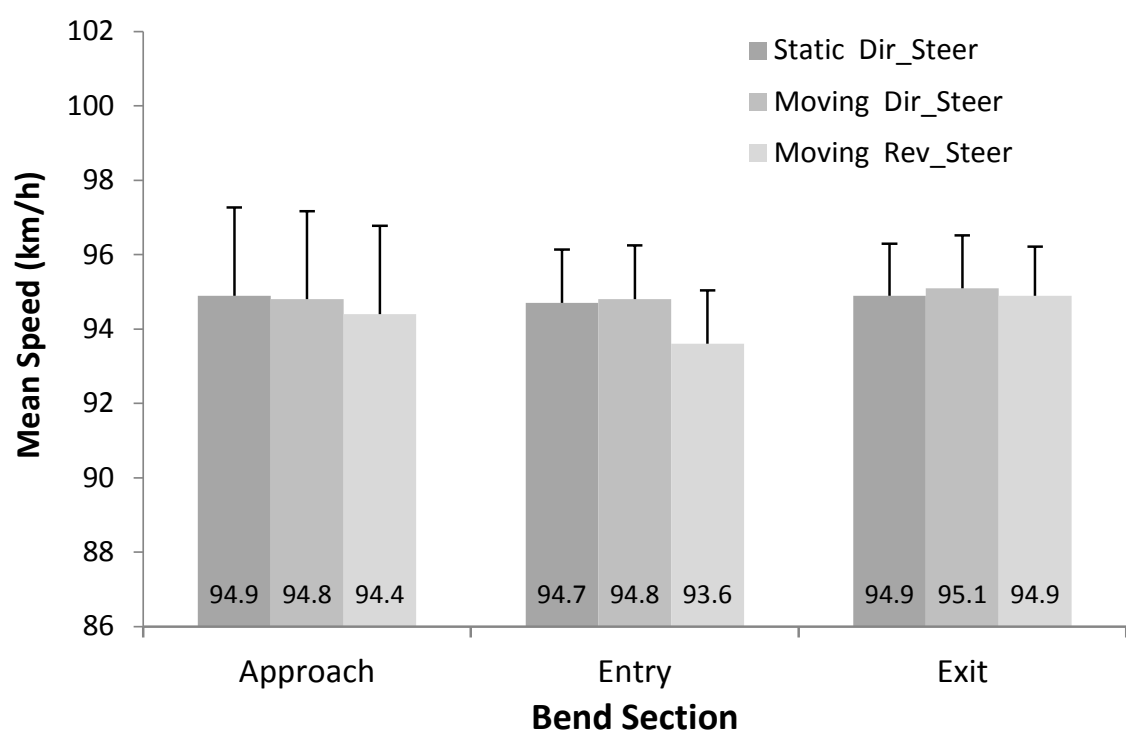

Figure 3. Mean speed $(\mathrm{km} / \mathrm{h})$ as a function of motorcycle simulator configuration and bend section. Error bars represent the standard error of the mean. 


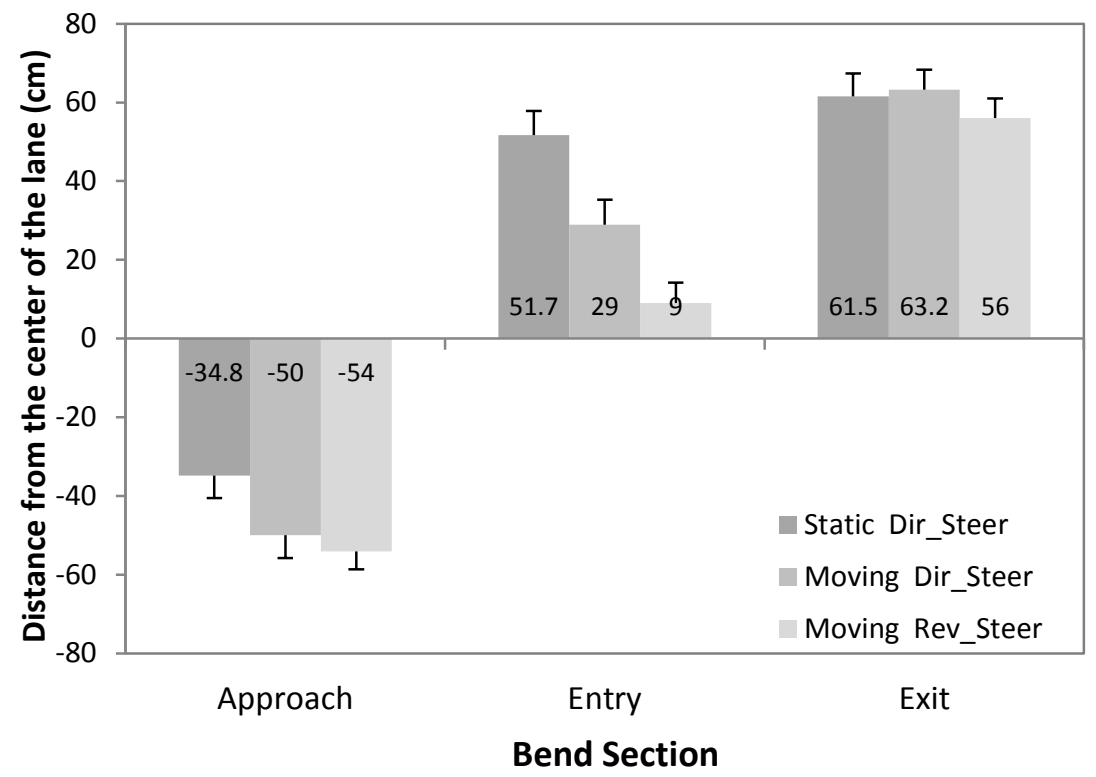

Figure 4. Lateral position in the lane (3.5 $\mathrm{m}$ wide) as a function of motorcycle simulator configuration and bend section. Lateral position is expressed as the distance $(\mathrm{cm})$ from the center of the lane. Negative value means that the riders rode in the outer part of the lane, whilst positive value means that they rode in the inside part. When positioned on average at $56 \mathrm{~cm}$ from the center of the lane, the riders were at $119 \mathrm{~cm}$ from the inside edge line. Error bars represent the standard error of the mean. 


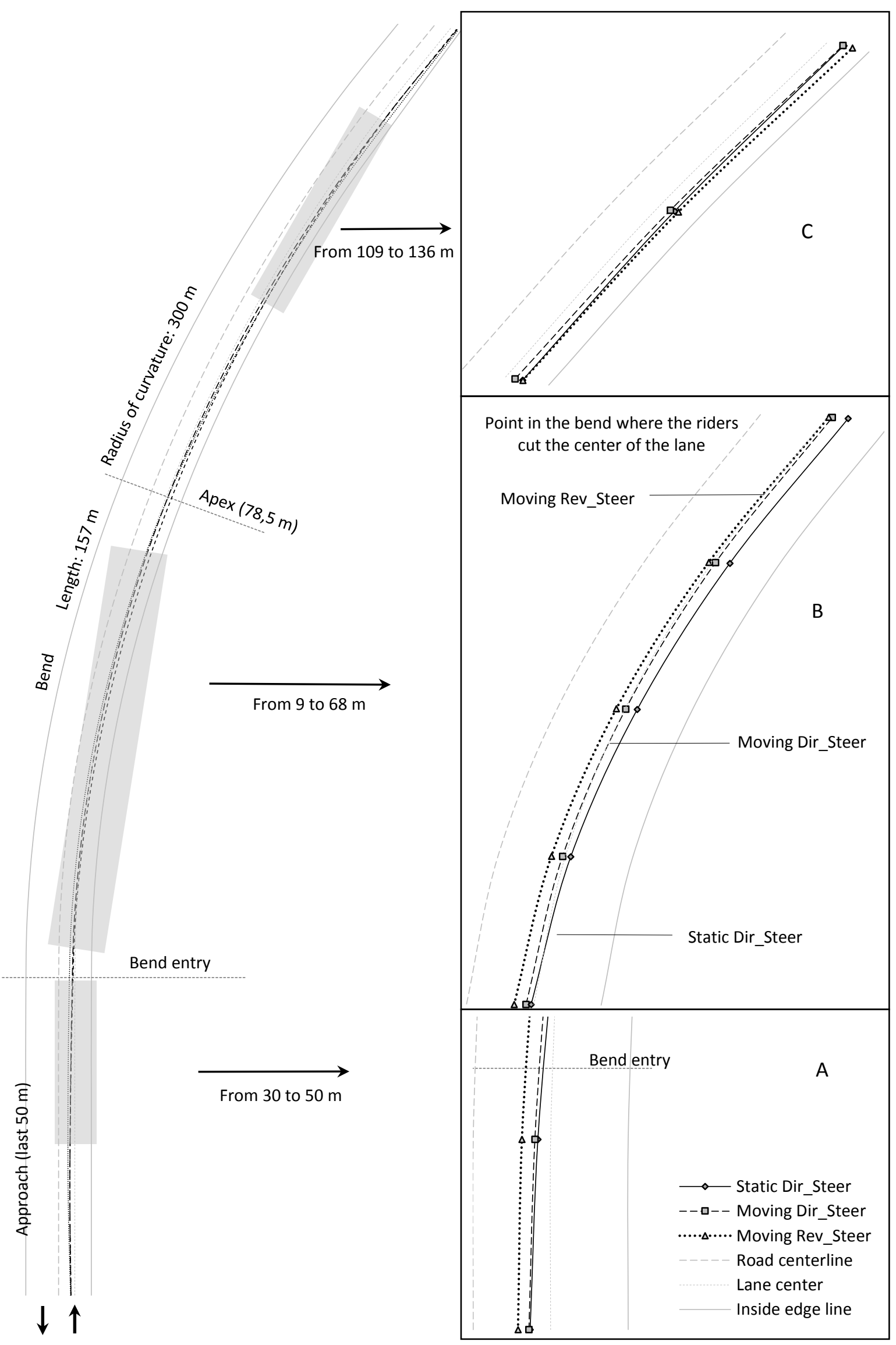


Figure 5. Trajectories averaged across the participants in a right-hand bend (Length: $157 \mathrm{~m}$;

Radius of curvature: $300 \mathrm{~m}$ ). The final $50 \mathrm{~m}$ of straight road before entering the curve (approach phase) are also represented. The left panel illustrates the three averaged trajectories when riding the three motorcycle simulator configurations, respectively. The right panel illustrates the three grey rectangles that correspond to three key points in the bend: (A) Lateral position of the motorcycle when approaching the bend, (B) Point in the bend where the riders cut across the center of their lane, and (C) Maximum lateral position the riders reached in that particular bend. 
1

2

3

4

5

6

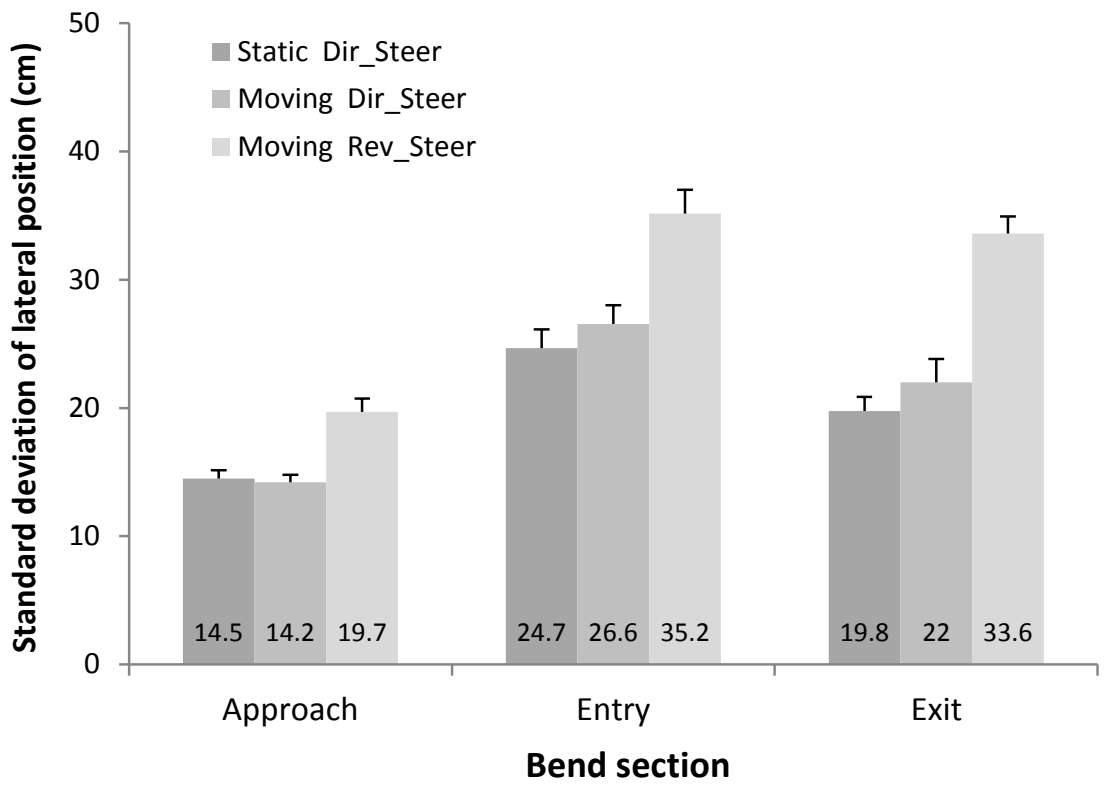

Figure 6. Standard deviation of lateral position as a function of motorcycle simulator configuration and bend section. Error bars represent the standard error of the mean. 


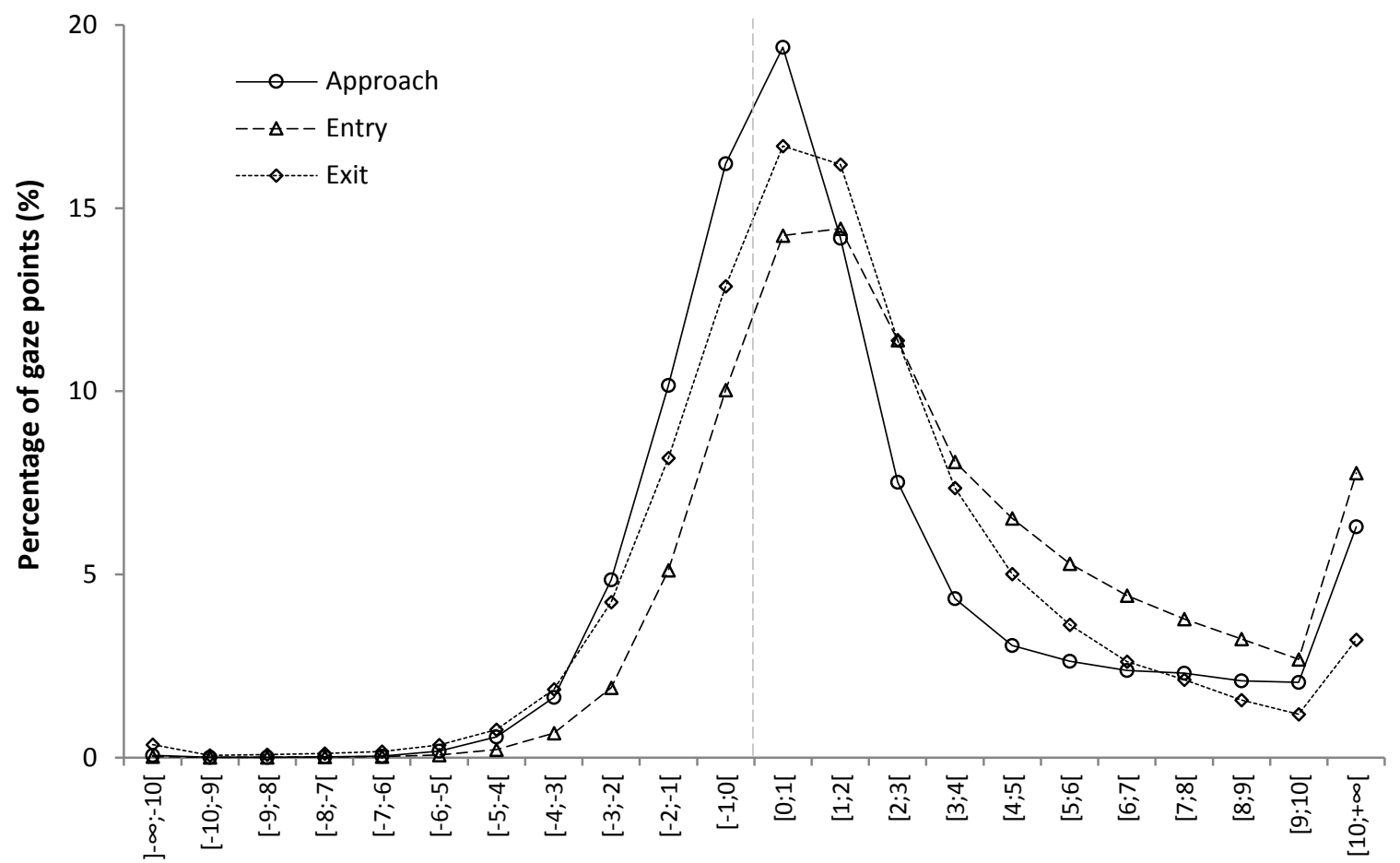

Angular deviation from the tangent point (degree)

Figure 7. Distribution of gaze points (as a percentage) as a function of bend section and angular deviation from the tangent point on the horizontal axis. Positive angular deviation means that gaze is directed toward the bend exit. The thin dashed line represents the tangent point position on the horizontal axis. 


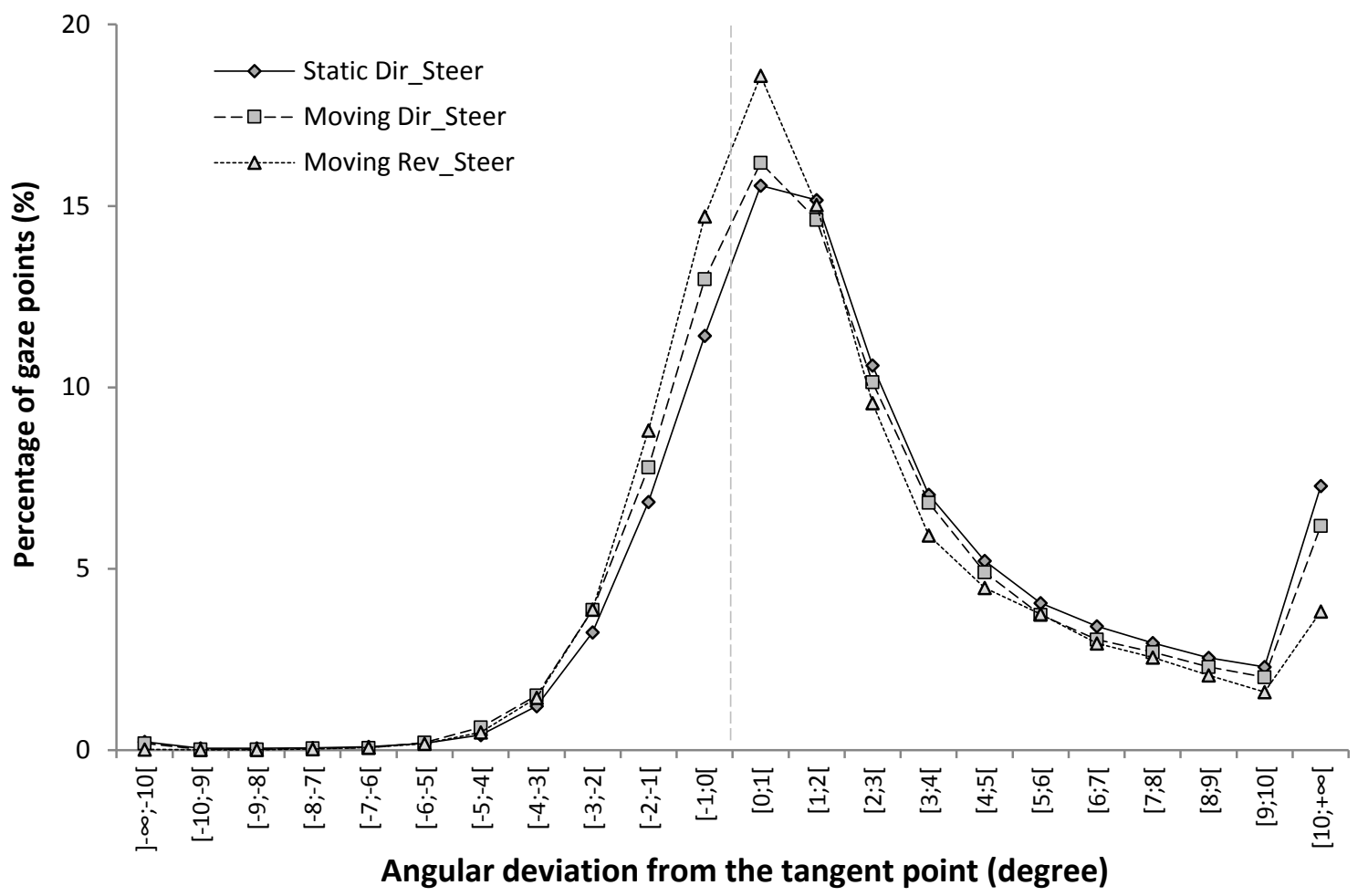

Figure 8. Distribution of gaze points (as a percentage) as a function of motorcycle simulator configuration and angular deviation from the tangent point on the horizontal axis. Positive angular deviation means that gaze is directed toward the bend exit. The thin dashed line represents the tangent point position on the horizontal axis. 